\title{
A New Paradigm for the North Pacific Subthermocline Low-Latitude Western Boundary Current System
}

\author{
Bo QIU AND SHUIMING CHEN \\ Department of Oceanography, University of Hawai'i at Mānoa, Honolulu, Hawaii \\ DANIEL L. RUDNICK \\ Scripps Institution of Oceanography, La Jolla, California \\ YUJI KASHINO \\ Center for Earth Information Science and Technology, Japan Agency for Marine-Earth Science \\ and Technology, Yokohama, Japan
}

(Manuscript received 13 February 2015, in final form 19 May 2015)

\begin{abstract}
Subthermocline western boundary circulation along the low-latitude North Pacific Ocean $\left(2^{\circ}-25^{\circ} \mathrm{N}\right)$ is investigated by using profiling float and historical CTD/expendable CTD (XCTD) data and by analyzing an eddy-resolving global OGCM output. In contrast to the existing paradigm depicting it as a reversed pattern of the wind-driven circulation above the ventilated thermocline (i.e., depth $<26.8 \sigma_{\theta}$ ), the subthermocline western boundary circulation is found to comprise two components governed by distinct dynamical processes. For meridional scales shorter than $400 \mathrm{~km}$, the boundary flows along the Philippine coast exhibit convergent patterns near $7^{\circ}, 10^{\circ}, 13^{\circ}$, and $18^{\circ} \mathrm{N}$, respectively. These short-scale boundary flows are driven by the subthermocline eastward zonal jets that exist coherently across the interior North Pacific basin and are generated by the triad instability of wind-forced annual baroclinic Rossby waves. For meridional scales longer than $400 \mathrm{~km}$, a time-mean Mindanao Undercurrent (MUC) is observed from $6^{\circ}$ to $13^{\circ} \mathrm{N}$ together with another northward-flowing boundary flow beneath the Kuroshio from $16^{\circ}$ to $24^{\circ} \mathrm{N}$. Rather than remote eddy forcing from the interior Pacific Ocean, both of these broad-scale subthermocline boundary flows are induced by baroclinic instability of the overlying wind-driven western boundary currents, the Mindanao Current, and Kuroshio.
\end{abstract}

\section{Introduction}

The large-scale ocean circulation above the winddriven ventilated thermocline in the northwestern Pacific basin (i.e., depth above $26.8 \sigma_{\theta}$ or $\sim 500 \mathrm{~m}$ ) is relatively well established. As depicted schematically by blue arrows in Fig. 1, the dominant wind-driven flows in the region include the North Equatorial Current (NEC) carrying the meridional Sverdrup transport westward along the zero wind stress curl latitude of $\sim 14^{\circ} \mathrm{N}$ [see Imawaki et al. (2013) and references therein]. After impinging upon the Philippine coast, the

Corresponding author address: Dr. Bo Qiu, Department of Oceanography, University of Hawai'i at Mānoa, 1000 Pope Road, Honolulu, HI 96822.

E-mail: bo@soest.hawaii.edu
NEC bifurcates into the northward-flowing Kuroshio and the southward-flowing Mindanao Current (MC), the two prominent western boundary currents in the North Pacific Ocean (e.g., Toole et al. 1988; Qiu and Lukas 1996). Heading equatorward and at the southern tip of the Mindanao Island near $5^{\circ} \mathrm{N}$, a significant portion of the $\mathrm{MC}$ veers eastward to form the North Equatorial Countercurrent (NECC), with the remaining portion intruding westward into the Celebes Sea and providing the source water for the Indonesian Throughflow (ITF; Lukas et al. 1991; Gordon and Fine 1996; Kashino et al. 2001). Serving as a boundary between the wind-driven North and South Pacific tropical gyres, the NECC is known to exhibit quasi-stationary meanders with ridges appearing near $130^{\circ}$ and $140^{\circ} \mathrm{E}$, respectively. The commonly known Mindanao Eddy and Halmahera Eddy are dynamically related to the 


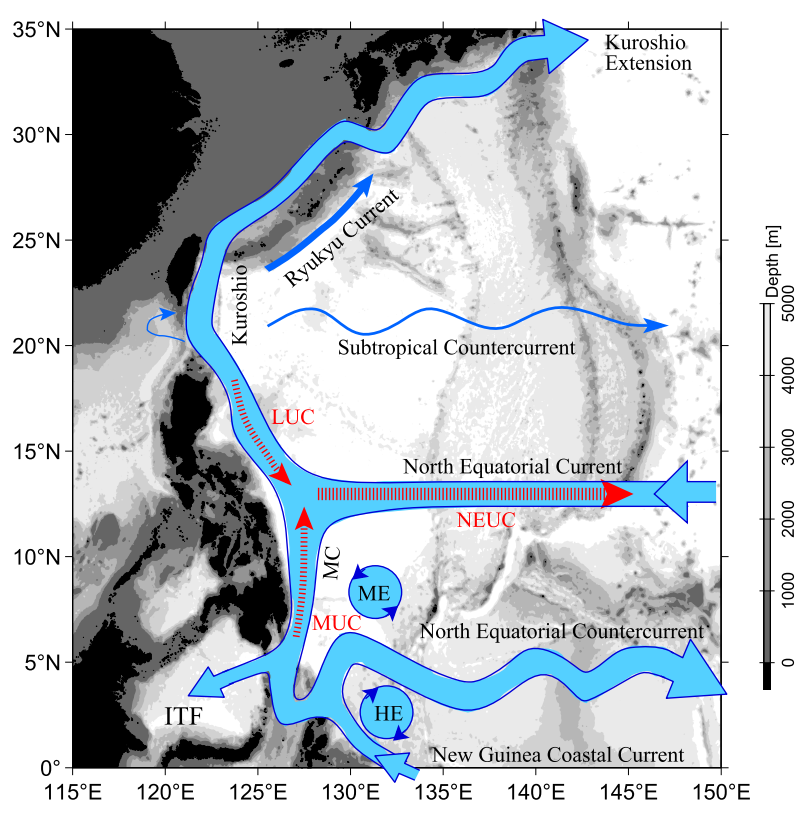

FIG. 1. Schematic circulation features within the ventilated thermocline (depth $<400 \mathrm{~m}$; blue arrows) and within the intermediate depth (500-2000 m; red arrows) in the western North Pacific. LUC, MUC, MC, ME, HE, NEUC, and ITF stand for Luzon Undercurrent, Mindanao Undercurrent, Mindanao Current, Mindanao Eddy, Halmahera Eddy, North Equatorial Undercurrent, and Indonesian Throughflow, respectively.

trough and ridge of the NECC's first quasi-stationary meander (e.g., Kashino et al. 2013).

North of the NEC bifurcation, the Kuroshio turns into a coherent and identifiable boundary jet east of Luzon Island at $16^{\circ}-18^{\circ} \mathrm{N}$ (e.g., Centurioni et al. 2004; Gordon et al. 2014). The Kuroshio strengthens further as it passes by the Luzon Strait and east of Taiwan because of the addition of mass transport from the winddriven interior Sverdrup gyre. Moored current meter observations show that the Kuroshio has a mean volume transport of 15.0 Sverdrups $\left(\mathrm{Sv} ; 1 \mathrm{~Sv} \equiv 10^{6} \mathrm{~m}^{3} \mathrm{~s}^{-1}\right)$ east of Luzon Island and 21.5 Sv east of Taiwan (Johns et al. 2001; Lee et al. 2001; Lien et al. 2014). North of $24^{\circ} \mathrm{N}$, the main part of the Kuroshio enters the East China Sea, and the other part branches eastward to form the Ryukyu Current east of the Ryukyu Island chain (e.g., Zhu et al. 2003; Nakamura et al. 2007). East of $130^{\circ} \mathrm{E}$, the Ryukyu Current joins the Kuroshio of the East China Sea after the latter exits the Tokara Strait, and together they form the downstream Kuroshio and its extension south and southeast of Japan.

The Kuroshio path and transport in the latitude band from $18^{\circ}$ to $24^{\circ} \mathrm{N}$ are highly variable due to the energetic, westward-propagating mesoscale eddies from the interior ocean (Zhang et al. 2001; Gilson and Roemmich 2002). These impinging eddies have a dominant period of 100 days and are generated along the North Pacific Subtropical Countercurrent (STCC) as a result of baroclinic instability between the surface eastward-flowing STCC and the subsurface westward-flowing NEC (Qiu 1999; Kobashi and Kawamura 2002). Perturbations induced by these impinging eddies force part of the northward-flowing Kuroshio to divert to the east of the Ryukyu Island chain, contributing to the formation of the nascent Ryukyu Current (Ichikawa et al. 2004; Andres et al. 2008).

It is worth emphasizing that these circulation features above the main thermocline are not only observationally well established, they are also dynamically adequately understood within the framework of the Sverdrup dynamics and ventilated thermocline theory (Talley 1985; Huang and Qiu 1994; Kobashi and Kubokawa 2012). Compared to this upper-ocean circulation pattern, flow features in the intermediate depth below the thermocline (i.e., 500-2000 m) in the northwestern Pacific Ocean remain observationally fragmentary and theoretically speculative. A schematic for the subthermocline circulation adopted commonly by past investigators is that of the red arrows in Fig. 1. It suggests, by and large, a reversed image to that of the wind-driven thermocline circulation, with a Luzon Undercurrent (LUC) heading equatorward beneath the Kuroshio (e.g., Qu et al. 1997; Hu et al. 2013; Wang et al. 2014) and a Mindanao Undercurrent (MUC) heading poleward beneath the MC (e.g., Hu and Cui 1991; Zhang et al. 2014). The convergent LUC and MUC are believed to form the eastward North Equatorial Undercurrent (NEUC) underneath the NEC (e.g., Hu and Cui 1991; Wang et al. 1998; Wang et al. 2015).

It is important to stress that the observational evidence and forcing mechanisms relating to the LUC and MUC remain elusive. Regarding the existence of LUC, much of the observational evidence comes from the $18^{\circ} \mathrm{N}$ latitude, where past hydrographic and mooring surveys had concentrated. Questions such as where the LUC originates, through what processes it is driven, and how it is connected to the eastward-flowing NEUC remain unanswered. Regarding the presence of the MUC, controversies have persisted in the past two decades. While hydrographic surveys by $\mathrm{Hu}$ and Cui (1991) and Qu et al. (1998) hinted at the existence of the MUC, subsequent analyses by Wijffels et al. (1995) and Firing et al. (2005) have pointed to the transient nature of the MUC related to westward-propagating mesoscale eddy variability. Similar uncertainties regarding the robustness of MUC are also evident in more recent moored current meter measurements off of Mindanao Island. Based on a $3-\mathrm{yr}$ mooring at $6^{\circ} 50^{\prime} \mathrm{N}$ and $126^{\circ} 43^{\prime} \mathrm{E}$, Kashino et al. (2005) captured no steady MUC at 700-m 
depth. In contrast, a recent 2 -yr mooring at $8^{\circ} \mathrm{N}$ and $127^{\circ} 03^{\prime} \mathrm{E}$ by Zhang et al. (2014) detected a time-mean MUC in the 600-1000-m layer. While observational investigations of the MUC abound, no dynamical explanations for its existence have been proffered so far. From a theoretical perspective, it is fundamentally questionable that the LUC and MUC, if they persist as time-mean flows, can be understood as the western boundary currents in the same sense as the Kuroshio and the MC that compensate for the interior Sverdrup circulations in order to close the wind-driven subtropical and tropical gyres. What, then, are the theoretical explanations relevant for the time-mean meridional flows along the North Pacific low-latitude western boundary beneath the ventilated thermocline?

With the establishment of the International Argo Program in the early 2000s (Roemmich et al. 2009), a new global profiling temperature-salinity $(T-S)$ dataset has become available for exploring the World Ocean subthermocline circulation patterns. In particular, the float sampling density off the Philippine coast is significantly enhanced by the deployment of 105 -day repeat SOLO-II floats as part of the Origins of the Kuroshio and Mindanao Currents (OKMC) project in 2011 (Qiu et al. 2013b). By combining the Argo and OKMC float $T-S$ data, Qiu et al. (2013b) examined the subthermocline flow structures across the North Pacific basin of $2^{\circ}-30^{\circ} \mathrm{N}$. Instead of a single eastward undercurrent beneath the NEC as depicted in Fig. 1, they discovered that the NEUC consists of three parallel eastward-flowing jets within the isopycnal layer of 26.8 $27.4 \sigma_{\theta}$ (approximately $500-1100-\mathrm{m}$ depth) along $9^{\circ}, 13^{\circ}$, and $18^{\circ} \mathrm{N}$ in the northwestern Pacific basin. These subthermocline NEUC jets have a typical core velocity of $2-5 \mathrm{~cm} \mathrm{~s}^{-1}$ and are spatially coherent from the western boundary to about $120^{\circ} \mathrm{W}$ across the North Pacific basin. Notice that the $9^{\circ} \mathrm{N}$ NEUC jet was also detected by Cravatte et al. (2012) in their analysis of the parking depth trajectory dataset of the Argo floats. In fact, Cravatte et al. found that the eastward subthermocline jets exist also beneath the NECC along $5^{\circ}$ and $2^{\circ} \mathrm{N}$ across the equatorial North Pacific basin.

To clarify the mechanisms responsible for these observed subthermocline zonal jets across the Pacific basin, Qiu et al. (2013a) analyzed output from an eddyresolving global OGCM output and identified that these subthermocline jets have a mode- 1 baroclinic vertical structure and are spatially persistent on interannual and longer time scales. By adopting a nonlinear 1.5-layer reduced-gravity model and the baroclinic Rossby wave triad interaction theory, Qiu et al. (2013a) showed that the seed for the NEUC jets originates in annual baroclinic Rossby waves driven by the basin-scale surface wind stress forcing. Emanating from the Pacific basin's eastern boundary, the wind-forced annual Rossby waves are subject to nonlinear triad interactions (Pedlosky 1987). They break down offshore where the $e$-folding time scale of the most unstable triad instability matches the advective time scale of the wind-forced "primary" waves (typically several thousands of kilometers off the North America coast at $10^{\circ} \mathrm{N}$ and a few hundreds of kilometers at $30^{\circ} \mathrm{N}$ ). With their meridional wavelength scales of $\sim 500 \mathrm{~km}$ set by the short secondary unstable waves, the time-mean NEUC jets are found to be generated by converging potential vorticity fluxes of the unstable nonlinear eddies.

Qiu et al. (2013a) have focused on the formation of the subthermocline jets inside the interior North Pacific basin. They did not explore how these interior jets behave near the Pacific western boundary and to what extent they are connected to the previously purported LUC and MUC beneath the Kuroshio and Mindanao Current. To address these questions, we deployed an additional set of 17 OKMC profiling floats near the Philippine coast in March 2013. With a 5-day repeat cycle, a significant amount of new $T-S$ data has become available in the Philippine Sea. In addition to the profiling float deployment, hydrographic surveys have also been conducted off the Luzon Island in 2012 and 2013 as part of the OKMC project (Gordon et al. 2014). These new datasets provide us now with a timely opportunity to reexamine, both observationally and dynamically, the detailed subthermocline circulation along the North Pacific low-latitude western boundary.

The present study has two objectives. First, we attempt to map out detailed time-mean circulation features along the Philippine coast by synthesizing all historical and modern $T-S$ measurements in the region. Particular attention will be given to the connectivity of the meridional subthermocline flows along the Philippine coast to those of the recently discovered alternating zonal jets in the interior basin. Our second objective is to clarify the dynamical processes governing the subthermocline low-latitude western boundary current circulation in the North Pacific Ocean on different spatial scales. With the aid of a high-resolution, eddy-resolving OGCM output, we will focus in particular on the formation of the time-mean MUC that has a meridional coherence from $6^{\circ}$ to $13^{\circ} \mathrm{N}$ in our mapped circulation along the Philippine coast.

\section{Hydrographic and profiling float data}

To adequately resolve the spatially detailed timemean circulation features near the low-latitude western 
(a) Argo/OKMC Profiles

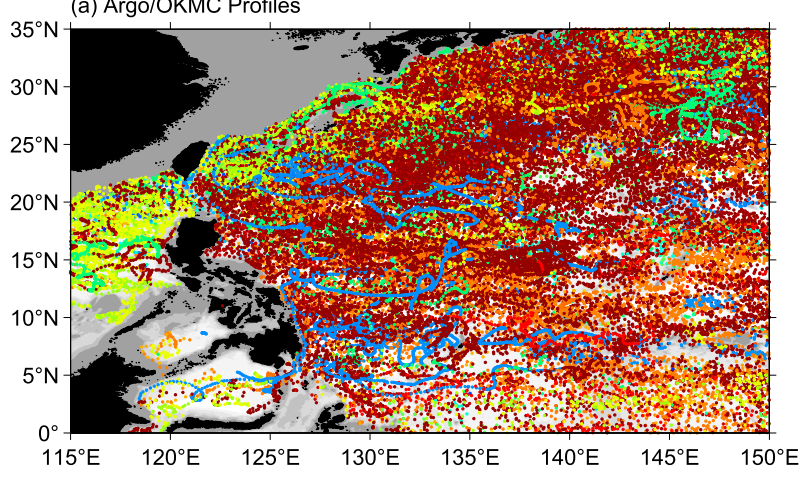

(b) Historical CTD Profiles

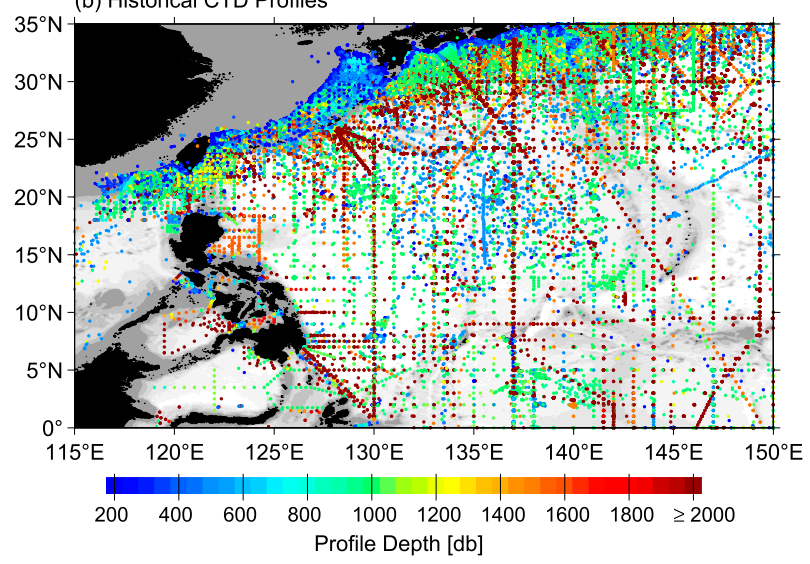

FIG. 2. Distributions of $T-S$ profiles from (a) the Argo and OKMC projects and (b) the historical CTD/XCTD surveys. Colors indicate the depth over which $T-S$ are measured. There are 74053 and 104063 profiles in (a) and (b), respectively.

boundary in the North Pacific Ocean, we collect the profiling float $T-S$ data from the International Argo Project (http://www.usgodae.org) from January 2001 to June 2014. All OKMC float data are embedded in the International Argo data stream. Figure 2a shows the distribution of the available Argo/OKMC profiles within the $0^{\circ}-35^{\circ} \mathrm{N}$ and $115^{\circ}-150^{\circ} \mathrm{E}$ domain of our interest. Most of the profiling float data reach the depth of 2000 dbar in the open Pacific Ocean. To enhance the quantity of the $T-S$ data especially off the Philippine coast, we also extract available conductivity-temperaturedepth (CTD) and expendable CTD (XCTD) data in the same domain archived by the U.S. National Oceanographic Data Center (NODC), the Japan Oceanographic Data Center (JODC), and the recent OKMC Lamon Bay cruises (Gordon et al. 2014). Unlike the profiling float data, many of the CTD/XCTD casts measure the full water depth $T-S$ values, and care has been taken to avoid duplicate casts in the different data sources.

For data quality control, we compare the individually measured $T-S$ values against the $1^{\circ} \times 1^{\circ}$ World Ocean
Atlas 2013 climatological data by Locarnini et al. (2013) and Zweng et al. (2013). The $T-S$ data are excluded if they fall outside of the two standard deviation envelopes of the local, climatological $T-S$ curve. For the 74053 float and $104063 \mathrm{CTD} / \mathrm{XCTD}$ profiles that passed the quality control procedure (those shown in Fig. 2), the $T-S$ data are first interpolated onto a regular 10 -m vertical grid between the surface and $2000 \mathrm{~m}$. At each depth, $T-S$ values are then mapped onto a $1 / 8^{\circ} \times 1 / 8^{\circ}$ grid using an objective mapping technique. The Gaussian weight function for mapping has a form of $\exp \left(-\Delta x^{2} / 2 L_{x}^{2}-\Delta y^{2} / 2 L_{y}^{2}\right)$, where $\Delta x$ and $\Delta y$ are the zonal and meridional distances between a data point and the grid point. For the spatial decorrelation scales, $L_{x}=$ $0.5^{\circ}$ in longitude and $L_{y}=0.5^{\circ}$ in latitude are chosen based on autocorrelations of the subthermocline $T-S$ field.

Unlike the previous studies that use the float trajectory data to derive the subthermocline circulation signals (e.g., Cravatte et al. 2012), we choose to describe the geostrophic circulation patterns relative to the $2000-\mathrm{m}$ depth. Our reasons for choosing this method over the float trajectory approach are twofold. First, the winddriven North Pacific subtropical gyre in the $10^{\circ}-30^{\circ} \mathrm{N}$ band is relatively shallow $(\sim 600 \mathrm{~m})$, and the flow amplitude at the $2000-\mathrm{m}$ level is on the order of $0.5 \mathrm{~cm} \mathrm{~s}^{-1}$, based on the previously estimated parking depth velocities of Lebedev et al. (2007) and Cravatte et al. (2012) plus the float-derived geostrophic shears. This magnitude of flow is on par with the uncertainties in estimating the parking depth velocity due to the imprecise float position fixes and spatial drifts when a float ascends and descends (e.g., Park et al. 2005; Chen et al. 2007). The second reason is that the subthermocline circulation of our interest is confined to the depth range of $300-1000 \mathrm{~m}$; its structures are insensitive to the addition of the 2000-m reference velocity [see Schönau and Rudnick (2015) for a favorable comparison between the glider-derived absolute geostrophic velocities versus those based on the Argo data referenced to $2000 \mathrm{~m}$ ]. Given the uncertainties in deriving the 2000-m reference velocity, we find it more straightforward to construct the three-dimensional circulation pattern in the upper $2000 \mathrm{~m}$ with a zero-referencing velocity.

\section{Observed circulation features}

Figure 3 shows the time-mean geostrophic velocity field in the surface 0-100-m layer in the western North Pacific Ocean. By and large, the broad-scale surface circulation conforms to the schematic blue arrows depicted in Fig. 1. Rather than a well-behaved convergent flow, however, Fig. 3 reveals that the NEC in the $7^{\circ}-$ $17^{\circ} \mathrm{N}$ band exhibits westward-fluctuating patterns. Such 


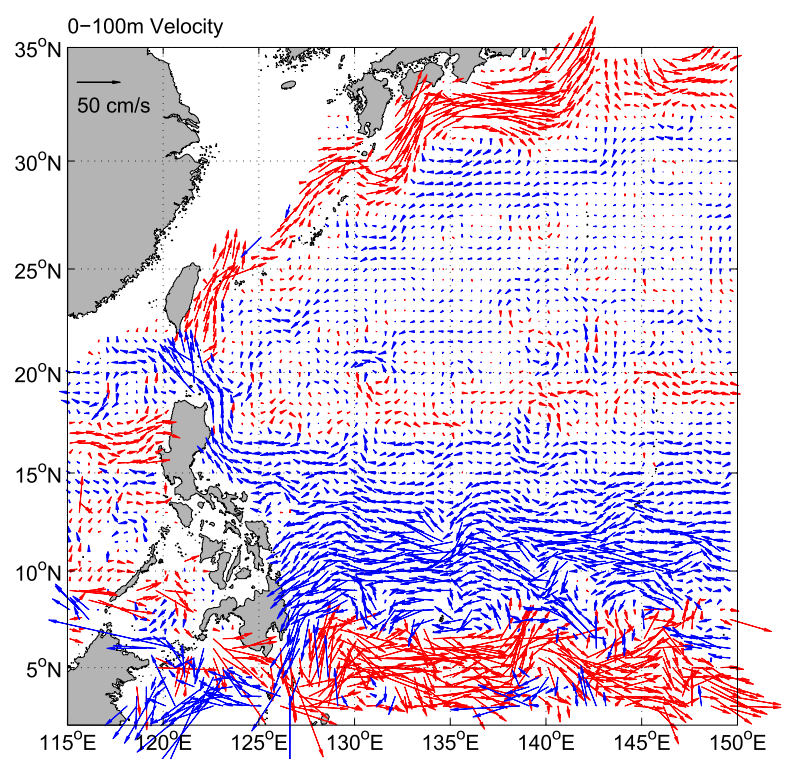

FIG. 3. Velocity vectors averaged in the surface $0-100-\mathrm{m}$ layer calculated geostrophically from the mapped $T-S$ field. Velocity vectors with an eastward (westward) component are plotted in red (blue).

fluctuations are likely caused by the presence of several meridionally aligned ridge systems over which the NEC has to traverse (i.e., the Kyushu-Palau Ridge along $\sim 135^{\circ} \mathrm{E}$, the South Honshu Ridge along $\sim 140^{\circ} \mathrm{E}$, and the East Mariana Ridge along $\sim 145^{\circ} \mathrm{E}$; see shaded bottom topography in Fig. 1). Notice that the westward-fluctuating $\mathrm{NEC}$ as a mean circulation feature in the western North Pacific was also noted recently by Vianna and Menezes (2010) in their analysis of high-resolution geodetic satellite mission data.

The Kuroshio can clearly be seen in Fig. 3 as originating in the NEC north of $\sim 12^{\circ} \mathrm{N}$. The Kuroshio's downstream evolution, including its intrusion into the South China Sea across the Luzon Strait, its bifurcation at the southern tip of the Ryukyu Island chain, and its meandering behavior south of Japan, is overall consistent with our current knowledge (e.g., Qiu 2001). One interesting feature that has not been previously noted is that there exists a southwestward flow offshore of the Ryukyu Current from south of Japan to east of the Luzon Strait that appears to feed continuously into the northeastward-flowing Kuroshio and Ryukyu Current. East of this southwestward flow in the $17^{\circ}-27^{\circ} \mathrm{N}$ band, the mean surface flow is often eastward and spatially fragmented. This corresponds to the STCC band, and its spatial incoherence is due to the regional enhanced eddy activities related to the baroclinically unstable STCCNEC system.

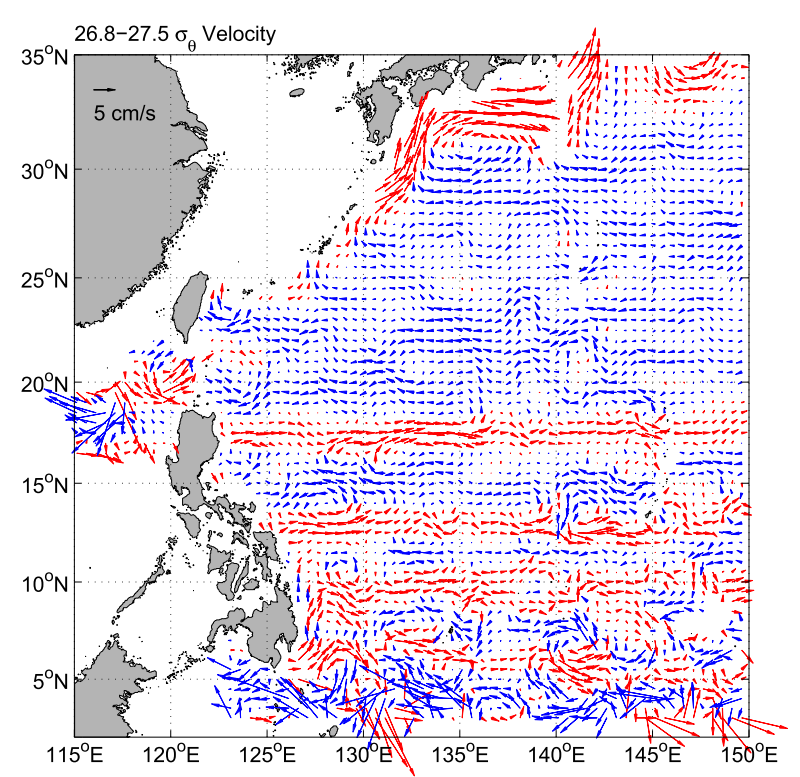

FIG. 4. As in Fig. 3, but for the subthermocline layer of 26.8-27.5 $\sigma_{\theta}$ $(\sim 500-1300 \mathrm{~m})$.

South of $12^{\circ} \mathrm{N}$, the commonly known features for the Mindanao Current, such as its westward intrusion into the Celebes Sea and its eastward veering to form the NECC, are well captured in Fig. 3. In agreement with the previous studies, two quasi-stationary meanders emerge along the NECC with their ridges near $130^{\circ}$ and $140^{\circ} \mathrm{E}$, respectively.

To represent the flow pattern below the wind-driven thermocline, we plot in Fig. 4 the geostrophic velocity vectors averaged in the 26.8-27.5 $\sigma_{\theta}$ layer (depth $\simeq 500$ $1300 \mathrm{~m}$ ). The flow pattern deviates qualitatively from the red arrows depicted in Fig. 1 in two fundamental ways: First, rather than a single NEUC flowing eastward beneath the core of the NEC, Fig. 4 reveals a series of eastward jets appear approximately along $6^{\circ}, 9^{\circ}, 13^{\circ}$, and $18^{\circ} \mathrm{N}$. These eastward jets are the same as those identified recently by Cravatte et al. (2012) and Qiu et al. (2013b). To clarify the vertical structures of the eastward jets, we plot in Fig. 5 the latitude-depth sections of zonal geostrophic velocity $U(y, z)$ along $130^{\circ}-135^{\circ} \mathrm{E}$ and $140^{\circ}-$ $145^{\circ} \mathrm{E}$. Comparing these two plots points clearly to the longitudinal persistence of the four eastward jets along $6^{\circ}, 9^{\circ}, 13^{\circ}$, and $18^{\circ} \mathrm{N}$. Notice that although weak in its strength, there is a hint in both sections that another eastward flow is present along $22^{\circ} \mathrm{N}$ with its core appearing below $27.5 \sigma_{\theta}$.

The second qualitative difference between the schematic of Figs. 1 and 4 is that while existing across $18^{\circ} \mathrm{N}$ along the Philippine coast below the 500-m depth (see also Fig. 6b) as reported in the literature (e.g., Qu et al. 1997; Hu et al. 2013; Wang et al. 2014), the LUC does not 
(a) $U g(y, z)$ and $\sigma_{\theta}(y, z): 130-135^{\circ} E$

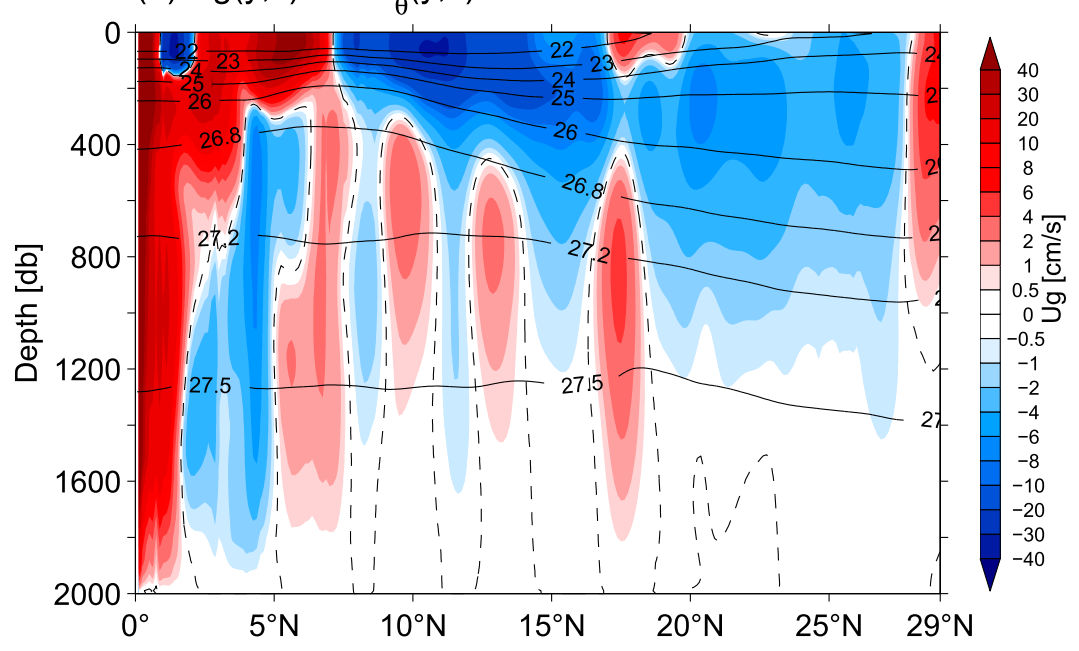

(b) $U g(y, z)$ and $\sigma_{\theta}(y, z): 140-145^{\circ} E$

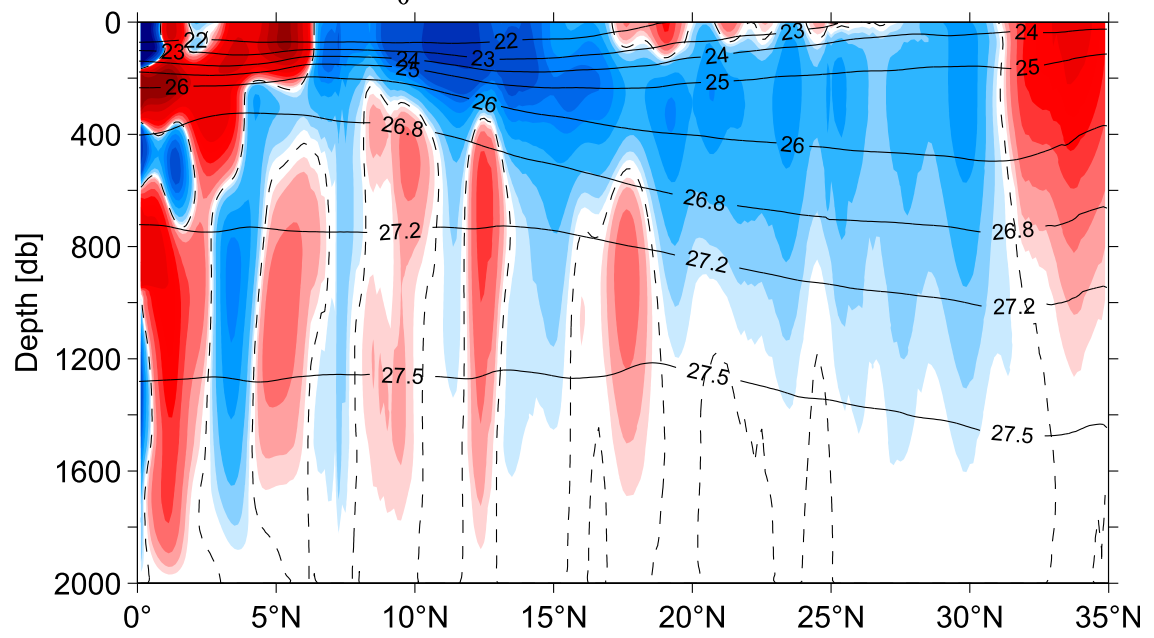

FIG. 5. Latitude-depth section of density (solid contours, $\sigma_{\theta}$ ) and zonal geostrophic velocity (color shading) along (a) $130^{\circ}-135^{\circ} \mathrm{E}$ and (b) $140^{\circ}-145^{\circ} \mathrm{E}$. The geostrophic velocity is referenced to $2000 \mathrm{~m}$, and dashed lines denote the zero velocity contours.

emerge as a coherent southward boundary current beneath the Kuroshio. For example, Figs. 6a and $6 \mathrm{c}$ show the meridional velocity sections across $20^{\circ}$ and $17^{\circ} \mathrm{N}$, respectively. Across both of these sections, a northward boundary flow paralleling the surface Kuroshio is present below the wind-driven thermocline or $26.8 \sigma_{\theta}$. With respect to the MUC beneath the wind-driven Mindanao Current, Fig. 4 reveals that a northward boundary current appears to persist from $6^{\circ}$ to $12^{\circ} \mathrm{N}$. This northward boundary current can also be confirmed in Figs. 6e and 6f, showing the meridional geostrophic velocity sections across $11^{\circ}$ and $8^{\circ} \mathrm{N}$, respectively. Notice that while being generally a northward subthermocline current, the MUC in Fig. 4 appears to wobble along the Philippine coast and that there is a hint that this wobbling is connected to the eastward jets existing in the interior Pacific Ocean.

To explore the flows along the western boundary in more detail, we plot in Fig. 7 the latitude-depth section of meridional geostrophic flow $V_{\mathrm{wb}}(y, z)$ averaged within a $2^{\circ}$-band along the Philippine coast and east of the Luzon Strait and Taiwan. In the upper ocean above $26.8 \sigma_{\theta}$ and impacted by the wind forcing, it is easy to discern the broad-scale northward-flowing Kuroshio and southward-flowing Mindanao Current. Consistent with previous data analysis and modeling studies by $\mathrm{Qu}$ and Lukas (2003) and Kim et al. (2004), the bifurcating latitude tends to shift poleward with increasing depth. Notice that the surface northward flow just north of the bifurcation point is weak and this is likely due to the 
(a) $\mathrm{Vg}$ along $20^{\circ} \mathrm{N}$

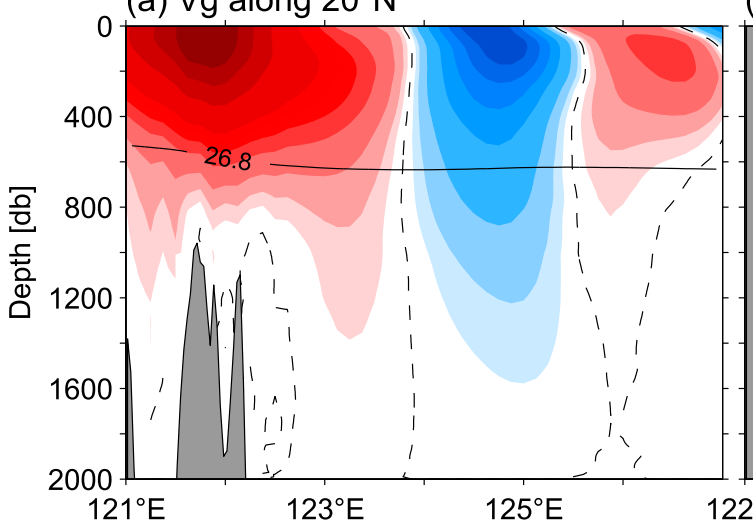

(c) $17^{\circ} \mathrm{N}$ (b) $18^{\circ} \mathrm{N}$

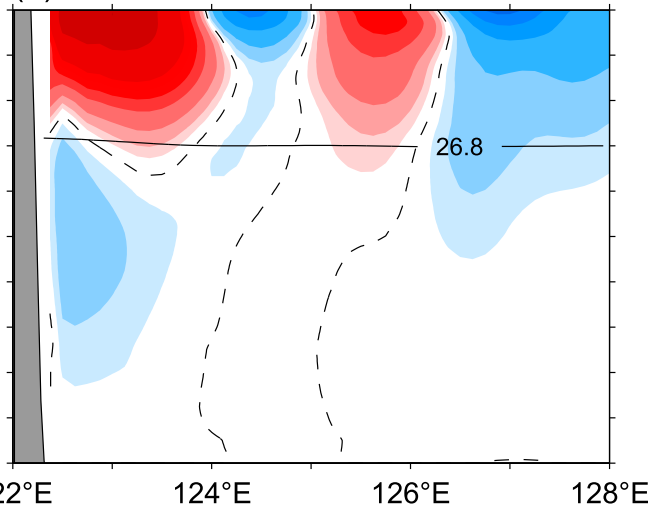

(d) $14^{\circ} \mathrm{N}$

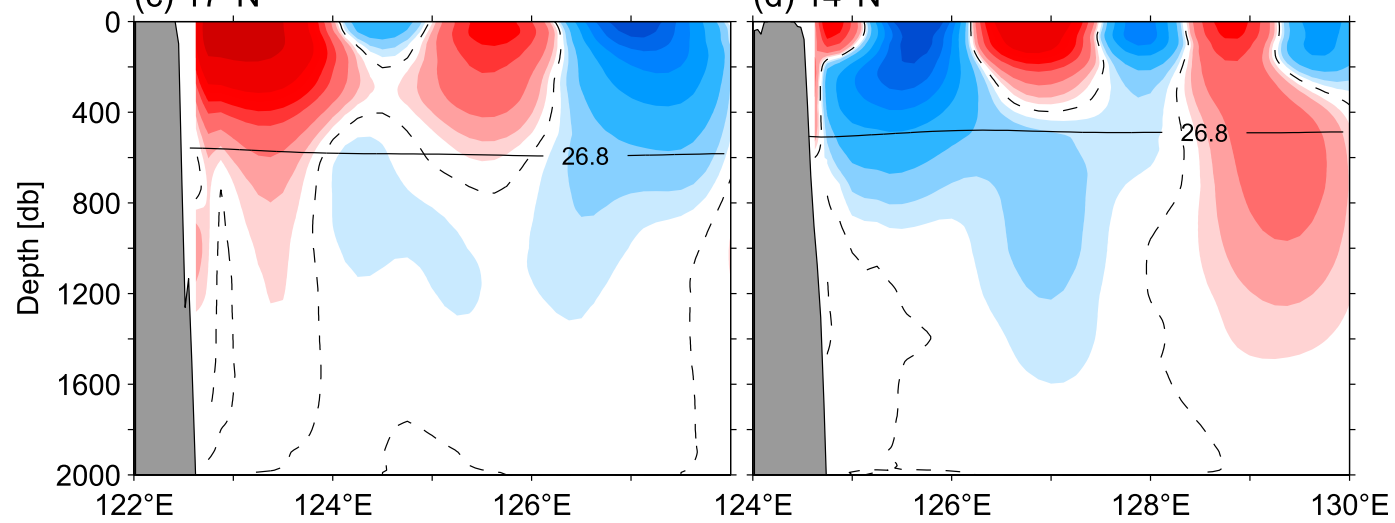

(e) $11^{\circ} \mathrm{N}$

(f) $8^{\circ} \mathrm{N}$

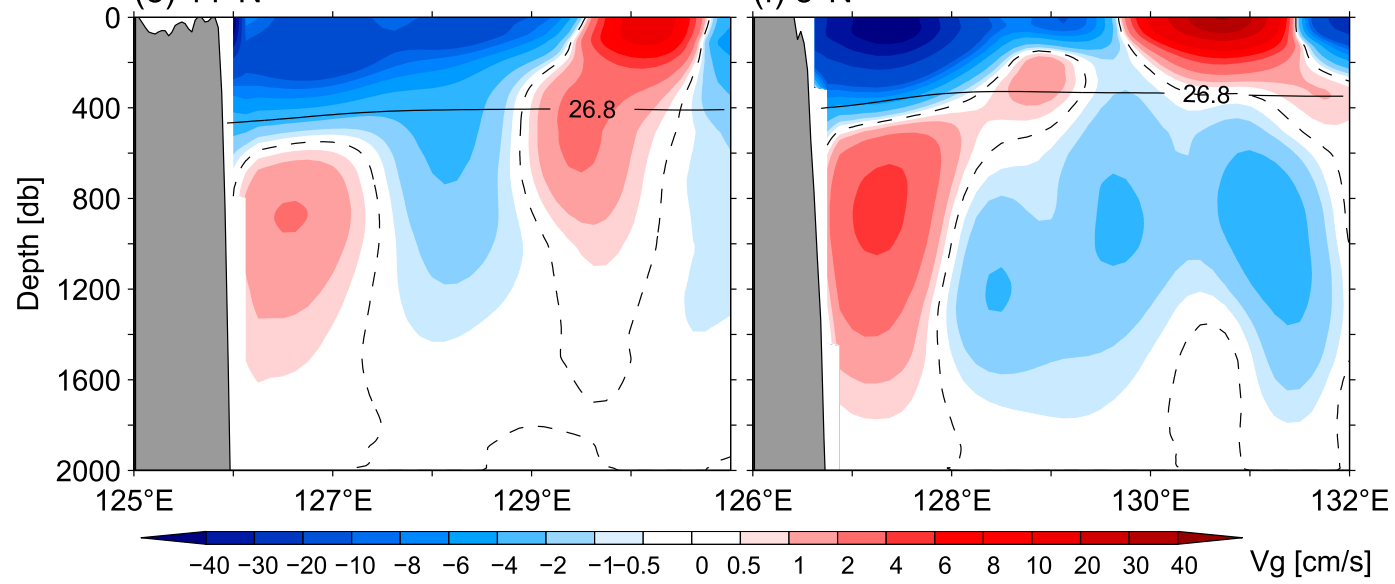

FIG. 6. Longitude-depth section of meridional geostrophic velocity along (a) $20^{\circ}$, (b) $18^{\circ}$, (c) $17^{\circ}$, (d) $14^{\circ}$, (e) $11^{\circ}$, and (f) $8^{\circ} \mathrm{N}$ off the Philippine coast and the Luzon Strait. The geostrophic velocity is referenced to $2000 \mathrm{~m}$, and dashed lines denote the zero velocity contours. Solid contours denote the $26.8 \sigma_{\theta}$.

topographic protrusion of the island Samar near the coastal segment of $13^{\circ}-14^{\circ} \mathrm{N}$.

Below the $26.8 \sigma_{\theta}$ isopycnal surface, the meridional velocities in Fig. 7 appear spatially fragmented. Specifically, $V_{\mathrm{wb}}$ appears alternating in direction north of $13^{\circ} \mathrm{N}$; south of $13^{\circ} \mathrm{N}$, while heading generally northward, the amplitude of $V_{\mathrm{wb}}$ appears to undulate with latitude.
To better understand these spatially undulating meridional flows along the western boundary, it is helpful to separate the $V_{\mathrm{wb}}(y, z)$ signals into those with long versus short meridional scales:

$$
V_{\mathrm{wb}}(y, z)=\tilde{V}_{\mathrm{wb}}(y, z)+V_{\mathrm{wb}}^{\prime}(y, z),
$$




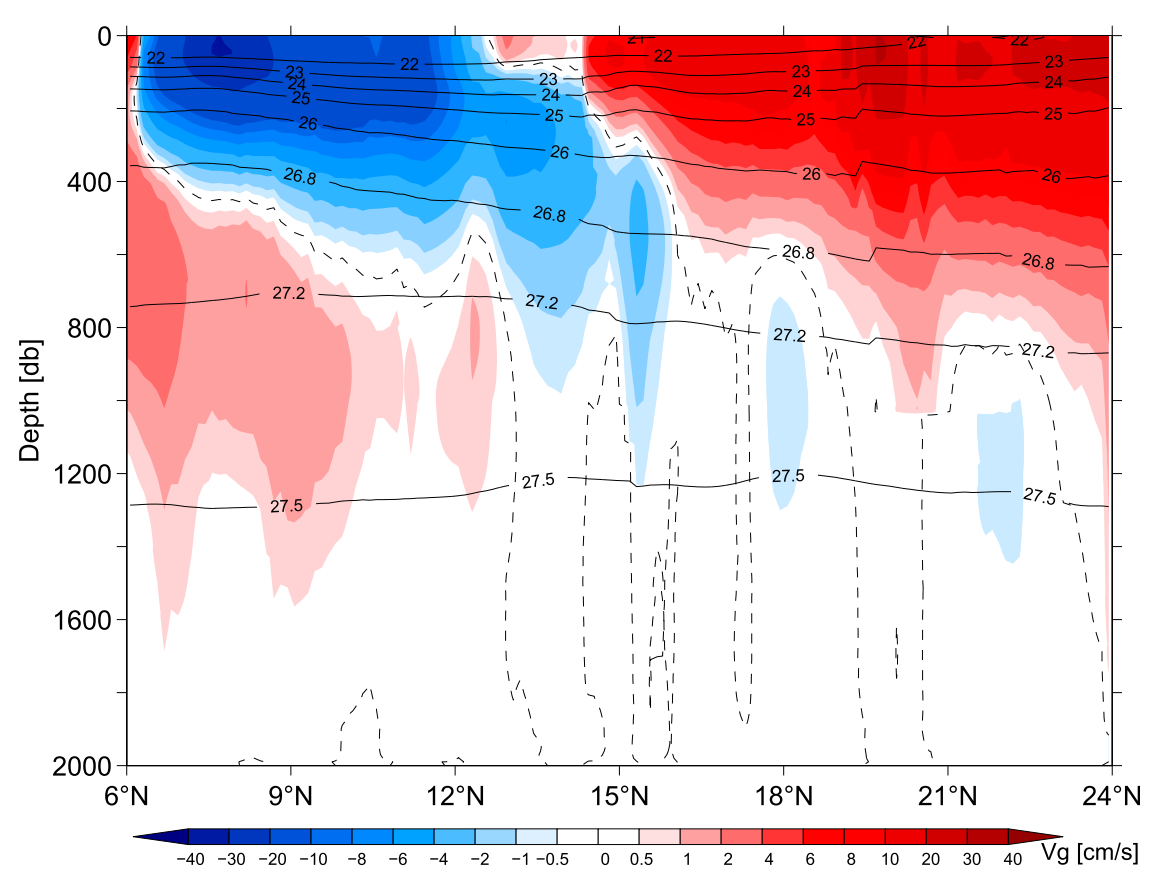

FIG. 7. Meridional geostrophic velocity (color shades) and density (solid contours) averaged in the $2^{\circ}$ band along the Philippine coast and east of the Luzon Strait and Taiwan. The geostrophic velocity is referenced to $2000 \mathrm{~m}$, and dashed lines denote the zero velocity contours.

where $\tilde{V}_{\text {wb }}$ denotes the low-pass filtered meridional velocity and $V_{\mathrm{wb}}^{\prime}$ denotes the remaining high-pass filtered component. Here, a $4^{\circ}$-box moving average is used as the spatial filter. Figure 8a shows the latitude-depth section of $V_{\mathrm{wb}}^{\prime}(y, z)$. Having removed the broad-scale signals, the meridionally alternating flow structures stand out prominently in Fig. 8a. Below $26.8 \sigma_{\theta}$, convergent meridional velocities can be seen near $7^{\circ}, 10^{\circ}$, $13^{\circ}$, and $18^{\circ} \mathrm{N}$ (see oppositely pointing arrows at $900-\mathrm{m}$ depth in Fig. 8a).

By applying the same high-pass spatial filtering to the $U(y, z)$ profile shown in Fig. 5a, Fig. 8b shows $U^{\prime}(y, z)$ along $130^{\circ}-135^{\circ} \mathrm{E}$. Near each latitude with a convergent $V_{\mathrm{wb}}^{\prime}$, one can identify a corresponding eastward $U^{\prime}$ signal. Dynamically this is not surprising because near the western boundary mass conservation requires

$$
U^{\prime}(y, z) \propto-\frac{\partial}{\partial y} V_{\mathrm{wb}}^{\prime}(y, z) .
$$

Notice that because of the meridionally varying topographic orientations and slopes, the convergent $V_{\mathrm{wb}}^{\prime}$ latitudes in Fig. 8a need not to match exactly the $U^{\prime}>0$ locations across the $130^{\circ}-135^{\circ} \mathrm{E}$ meridians. As noted in the introduction, our recent study has shown that the observed subthermocline eastward jets are generated by the breakdown of wind-forced annual baroclinic Rossby waves in the eastern North Pacific Ocean (Qiu et al. 2013a). Given this, the eastward $U^{\prime}$ jets shown in Fig. $8 \mathrm{~b}$ can be interpreted as the driver of the convergent $V_{\mathrm{wb}}^{\prime}$ flows along the western boundary rather than the other way around. Because the instability-induced eastward jets in the interior Pacific Ocean (Fig. 8b) have a baroclinic mode-1 vertical structure, it is not surprising to find in Fig. 8a that the $V_{\mathrm{wb}}^{\prime}$ signals exhibit vertically coherent signals above the $1500-\mathrm{m}$ depth. ${ }^{1}$

\section{The broad-scale Mindanao Undercurrent}

From Fig. 7, we have noted the existence of a broadscale poleward subthermocline flow south of $13^{\circ} \mathrm{N}$ along the Philippine coast. This poleward flow becomes much clearer if we plot the low-pass filtered $\tilde{V}_{\text {wb }}(y, z)$ profile defined in Eq. (1). As shown in Fig. 9, the subthermocline alongshore poleward flow slides downward from 26.8 to $27.5 \sigma_{\theta}$ as it moves northward. Its northern edge below $27.5 \sigma_{\theta}$ is at $13.5^{\circ} \mathrm{N}$, close to the NEC bifurcation latitude at the surface. Geographically, this broad-scale poleward boundary flow corresponds to the MUC identified by many previous studies. It is important to emphasize from Fig. 9 that there exists no

\footnotetext{
${ }^{1}$ The baroclinic mode- 1 structure in the northwestern Pacific Ocean has a zero crossing at $\sim 1400 \mathrm{~m}$.
} 
(a) Highpass Filtered $\mathrm{Vg}(\mathrm{y}, \mathrm{z})$

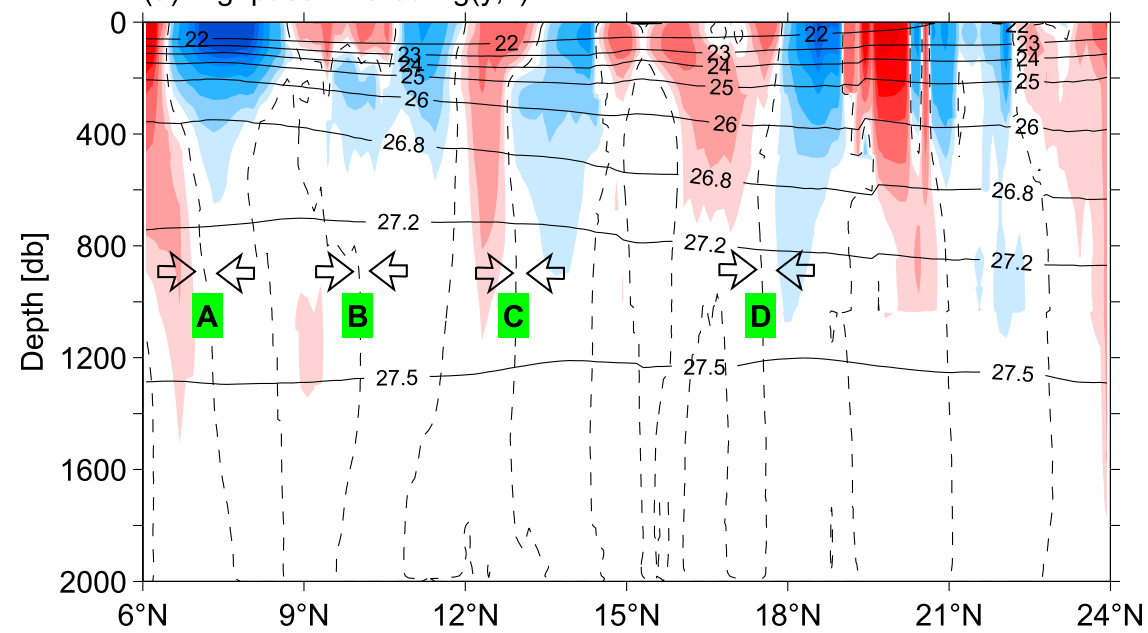

(b) Highpass Filtered Ug(y,z): $130-135^{\circ} \mathrm{E}$

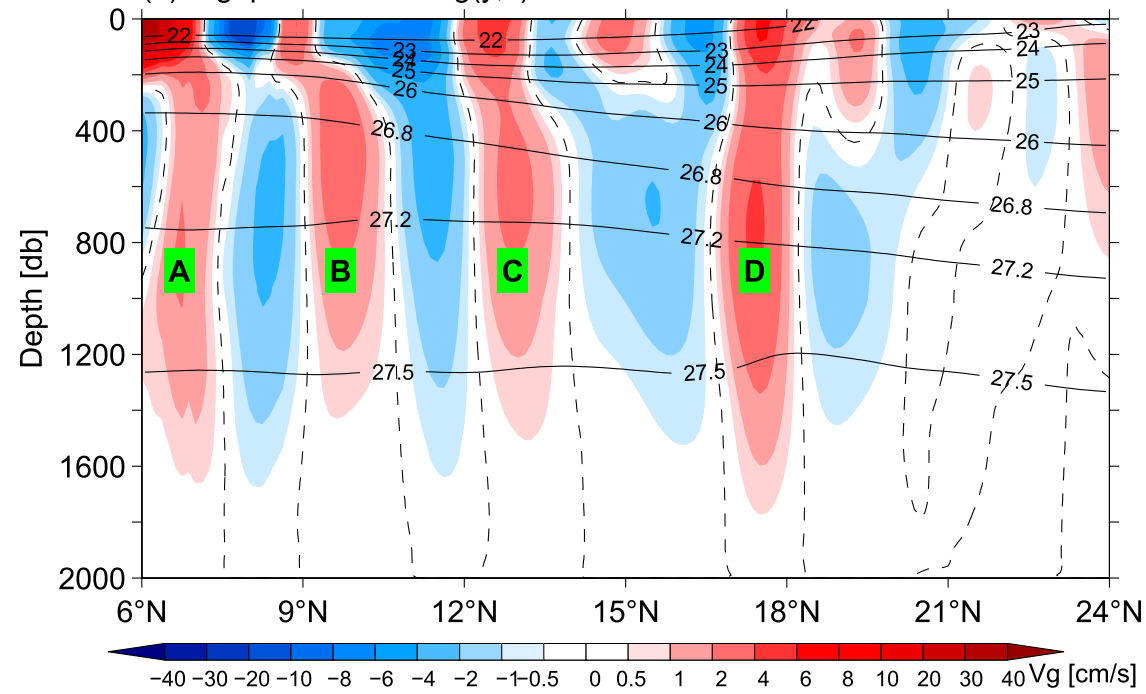

FIG. 8. Meridional-depth sections of (a) high-pass filtered $\mathrm{V}_{g}$ along the Philippine coast and east of the Luzon Strait and Taiwan, and (b) high-pass filtered $\mathrm{U}_{g}$ along $130^{\circ}-135^{\circ} \mathrm{E}$. The highpass filter removes signals using a $4^{\circ}$-box moving average. Arrows in (a) denote the directions of the subthermocline meridional flows and boxed letters, their convergent locations. Boxed letters in (b) denote the subthermocline eastward jet locations. Black contours in both plots indicate the isopycnal surfaces.

appreciable broad-scale southward-flowing boundary current north of $13^{\circ} \mathrm{N}$ below the $27.2 \sigma_{\theta}$ isopycnal. In other words, the LUC present across the $18^{\circ} \mathrm{N}$ parallel below the Kuroshio is a meridionally confined feature whose existence, as we have noted in the preceding section, is due to the NEUC jet along $18^{\circ} \mathrm{N}$ that results in the convergent meridional flows along the Philippine coast.

Regarding the broad-scale northward-flowing MUC identified in Fig. 9, no proper dynamical mechanisms have been identified in the past investigations (see the introduction). To clarify the MUC's generation mechanism, we examine in this section the model output from a multidecadal hindcast run of the OGCM for the Earth Simulator (OFES; Sasaki et al. 2008). The OFES model covers the global domain from $75^{\circ} \mathrm{S}$ to $75^{\circ} \mathrm{N}$ and has an eddy-resolving horizontal resolution of $0.1^{\circ}$ and 54 vertical levels. The model was spun up for $50 \mathrm{yr}$ with monthly climatological atmospheric forcing from the National Centers for Environmental Prediction-National Center for Atmospheric Research (NCEP-NCAR) reanalysis (Kistler et al. 2001). This climatological run was followed by a $62-\mathrm{yr}$ hindcast integration for the period of 1950-2011 using the NCEP-NCAR reanalysis daily 


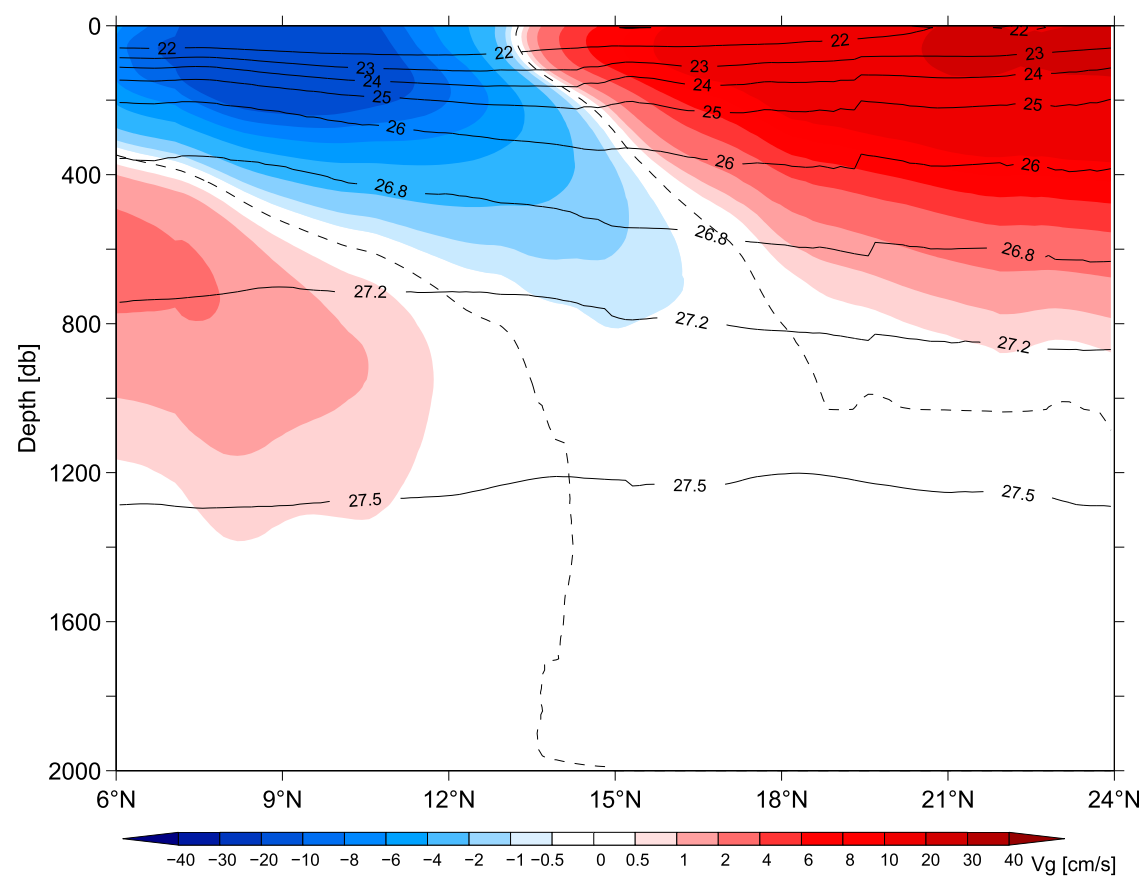

FIG. 9. Low-pass filtered meridional geostrophic velocity (color shades) averaged in the $2^{\circ}$-band along the Philippine coast and east of the Luzon Strait and Taiwan. The low-pass filter removes signals using a $4^{\circ}$-box moving average. Black contours indicate the isopycnal surfaces.

mean forcing data. In our following analyses, the 3-day model output from the hindcast run during 2001-11 was analyzed.

Figure 10 shows the velocity field in the $26.8-27.5 \sigma_{\theta}$ layer averaged from 2001 to 2011 based on the OFES hindcast output. Overall, the modeled flow pattern compares favorably with the observed flow field presented in Fig. 4. For example, the modeled zonal flows exhibit eastward jets along $6^{\circ}, 9^{\circ}, 13^{\circ}$, and $18^{\circ} \mathrm{N}$, similar to those identified in Fig. 4. Despite having the weaker amplitudes, the modeled NEUC jets also have comparable meridional profiles as those in the observations (cf. Figs. 11a and 5a). Along the low-latitude western boundary, Fig. 10 indicates that the poleward-flowing MUC wobbles in a manner consistent with the observed time-mean MUC. In fact, plotting the modeled $V_{\mathrm{wb}}(y, z)$ profile along the Philippine coast (Fig. 11b) reveals that the modeled MUC extends northward to $\sim 14^{\circ} \mathrm{N}$, a latitude detected similarly from the $T-S$ measurements. With respect to the southward flows present below the 1200-m depth, or the $27.5 \sigma_{\theta}$ isopycnal, in Fig. 11b, they should not be regarded as the LUC that has been observed and defined for the subthermocline layer of 26.8 $27.5 \sigma_{\theta}$.

This success of the OFES model in simulating the time-mean MUC provides us with a good opportunity to explore the MUC's formation mechanism with the use of the model output. Shielded from the direct wind forcing in the subthermocline North Pacific Ocean, the time-mean circulation likely follows the turbulent Sverdrup balance theorized by Rhines and Holland (1979):

$$
\overline{\mathbf{u}} \cdot \nabla \bar{Q} \simeq-\nabla \cdot\left(\overline{\mathbf{u}^{\prime} Q^{\prime}}\right),
$$

where $\mathbf{u}$ is the velocity vector in the $26.8-27.5 \sigma_{\theta}$ layer of our interest, and $Q$ is the potential vorticity $(\mathrm{PV})$ averaged in the same isopycnal layer:

$$
Q=f_{o}+\beta y+\zeta+f_{o} \frac{\partial \sigma_{\theta} / \partial z}{\partial\left\langle\overline{\sigma_{\theta}}\right\rangle / \partial z},
$$

where $f_{o}$ is the Coriolis parameter at the reference latitude $\left(12^{\circ} \mathrm{N}\right.$ here $), \beta$ is the latitudinal gradient of $f, \zeta$ is the relative vorticity, $\sigma_{\theta}$ is the potential density, and \langle\rangle denotes the spatial average in the analysis domain (see Fig. 12). In both Eqs. (3) and (4), overbars denote timemean quantities and primes denote anomalies from the time-mean values. Dynamically, Eq. (3) relates the timemean flow generated across the mean PV gradient to the convergence of eddy PV fluxes.

To test the validity of the turbulent Sverdrup balance, we evaluate in Figs. 12a and $12 \mathrm{~b}$ the LHS and RHS of Eq. (3) averaged in the 26.8-27.5 $\sigma_{\theta}$ layer based on the 3-day OFES output from 2001 to 2011. Geographically, 


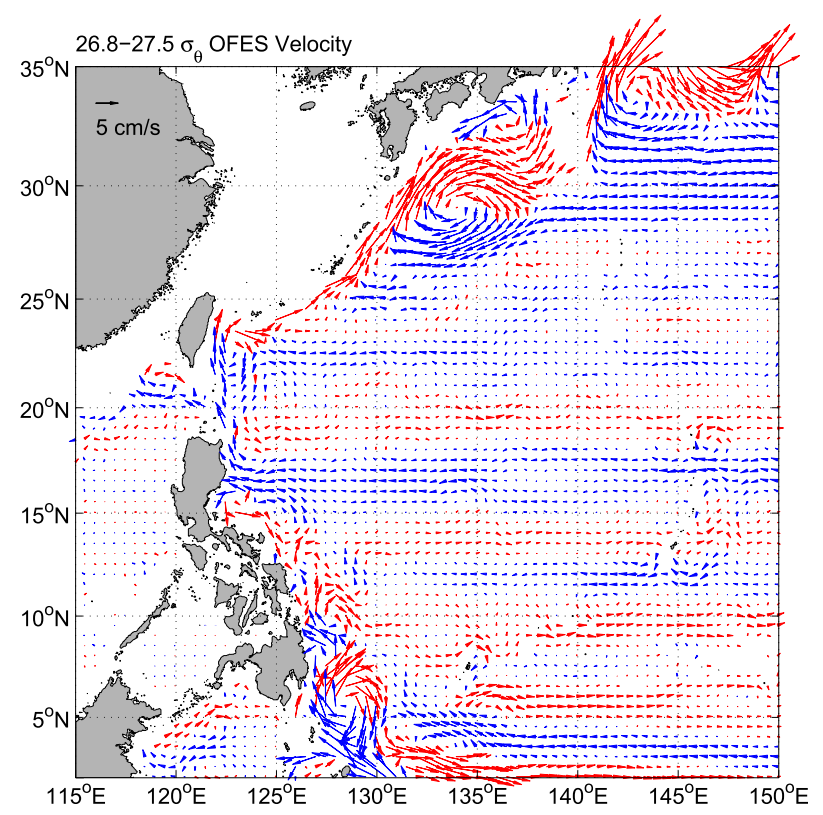

FIG. 10. Velocity vectors averaged in the subthermocline layer of 26.8-27.5 $\sigma_{\theta}(\sim 500-1300 \mathrm{~m})$ calculated from the OFES model output. Velocity vectors with an eastward (westward) component are plotted in red (blue).

there exists a good correspondence between these two terms; specifically, both terms tend to have large positive values along the western boundary and negative values farther offshore. An exception to this appears near $13^{\circ}-$ $15^{\circ} \mathrm{N}$ where the signs of the two terms have a reversed zonal structure. Notice that Fig. $12 \mathrm{~b}$ reveals no alternatingly signed eddy PV flux convergences of $\sim 200-\mathrm{km}$ length scales along the western boundary, which would have been required if the convergent meridional flow shown in Fig. 8a were due to the local eddy PV flux forcing. Because the time-mean PV gradient in the meridional direction greatly exceeds that in the zonal direction, the LHS of Eq. (3) can be approximated by $\bar{v} \partial \bar{Q} / \partial y$. Under this assumption, the eddy-driven meridional velocity $\bar{v}$ may be evaluated straightforwardly from $-\nabla \cdot\left(\overline{\mathbf{u}^{\prime} Q^{\prime}}\right) /(\partial \bar{Q} / \partial y)$. In Figs. $12 \mathrm{c}$ and $12 \mathrm{~d}$, we compare the $\bar{v}$ distribution from this approximate formulation and from the OFES model in the 26.8-27.5 $\sigma_{\theta}$ layer. The favorable correspondence between the two distributions is evident, suggesting that the broad-scale time-mean MUC observed along the Philippine coast of $6^{\circ}-13^{\circ} \mathrm{N}$ is driven by the convergent eddy PV fluxes via the turbulent Sverdrup balance.

To clarify the processes generating the subthermocline eddy fluxes, we plot in Fig. 13 the baroclinic and barotropic eddy energy conversion rate distributions in the wind-driven thermocline layer (Figs. 13a,b) and the subthermocline 26.8-27.5 $\sigma_{\theta}$ layer (Figs. 13c,d), respectively. Here, the two conversion rates are defined by

$$
\text { baroclinic conversion rate }=-\frac{g}{\rho_{o}}\left(\overline{\rho^{\prime} w^{\prime}}\right),
$$

and

$$
\text { barotropic conversion rate }=-\left(\overline{u_{i}^{\prime} u_{j}^{\prime}}\right) \frac{\partial \overline{u_{i}}}{\partial x_{j}},
$$

where $\rho^{\prime}$ and $w^{\prime}$ denote the potential density and vertical velocity anomalies from their respective time means, and summations over the repeated indices $i$ and $j$ are assumed in Eq. (6). Physically, Eq. (5) indicates the conversion from eddy potential energy to eddy kinetic energy and is the source for baroclinic instability, and Eq. (6) represents the conversion from mean kinetic energy to eddy kinetic energy through Reynolds stresses and is the cause for barotropic instability. Along the Philippine coast from $6^{\circ}$ to $13^{\circ} \mathrm{N}$, Fig. 13 reveals that the baroclinic conversion rate is consistently positive both in the thermocline and subthermocline layers (note that the contour intervals are 5 times smaller in Fig. 13c than in Fig. 13a). In contrast, the barotropic conversion rate appears mostly negative. This suggests that the flow variability generating the eddy PV flux convergence along the Philippine coast of Fig. $12 \mathrm{~b}$ is due to the release of mean available potential energy associated with the thermocline tilt of the winddriven Mindanao Current. While large in magnitude, the lateral shear of the Mindanao Current (see, e.g., Fig. 6f) contributes little to the generation of regional thermocline/ subthermocline eddy fluctuations.

In concluding this section, it is interesting to emphasize that Fig. 12 reveals that the eddy PV flux convergence also generates a time-mean northward boundary flow from $16^{\circ}$ to $24^{\circ} \mathrm{N}$ in the subthermocline $26.8-27.5 \sigma_{\theta}$ layer. As indicated in Fig. 11b, this eddy-driven boundary flow causes the wind-driven Kuroshio in the upper ocean to extend below the ventilated thermocline and its existence is discernible in the observed $\tilde{V}_{\text {wb }}$ profile shown in Fig. 9b as well. That the northward-flowing Kuroshio can extend to below the $26.8 \sigma_{\theta}$ depth was previously captured by in situ measurements along $\sim 24.3^{\circ} \mathrm{N}$ east of Taiwan (Zhang et al. 2001, see their Fig. 2b).

\section{Summary}

By synthesizing the temperature and salinity data from historical CTD/XCTD measurements and from more recent profiling float measurements of the International Argo and OKMC projects, we investigated in this study the detailed circulation features in the northwestern $\mathrm{Pa}$ cific Ocean. The focus of our investigation was on the 
(a) OFES $U(y, z)$ and $\sigma_{\theta}(y, z): 130-135^{\circ} E$

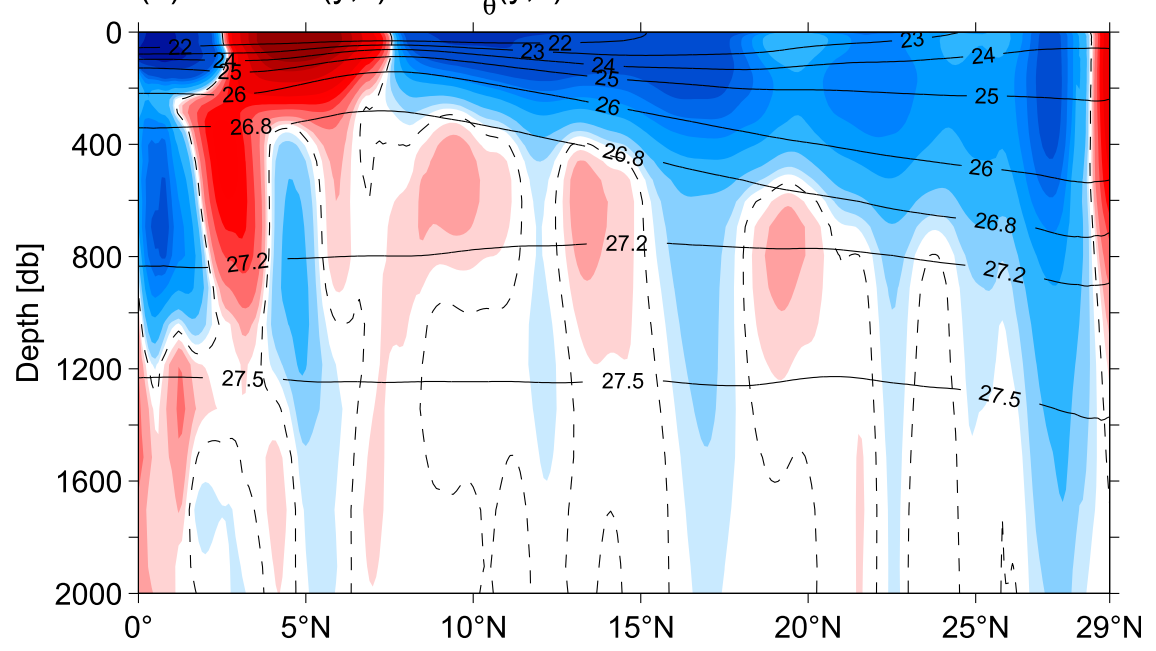

(b) OFES $\vee(y, z)$ and $\sigma_{\theta}(y, z)$ along the Coast

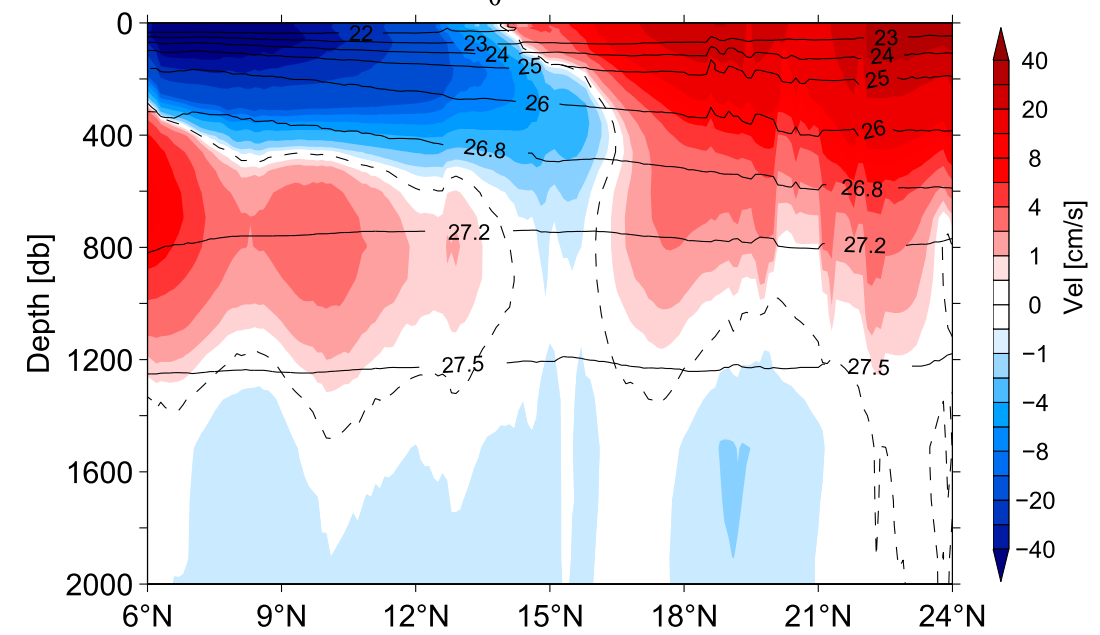

FIG. 11. (a) Latitude-depth section of density (solid contours, $\sigma_{\theta}$ ) and zonal velocity (color shading) along $130^{\circ}-135^{\circ} \mathrm{E}$ from the OFES simulation. (b) Latitude-depth section of density (solid contours, $\sigma_{\theta}$ ) and meridional velocity (color shading) from the OFES simulation along the Philippine coast and east of the Luzon Strait and Taiwan.

time-mean western boundary circulation system in the 26.8-27.5 $\sigma_{\theta}$ layer below the ventilated thermocline along the Philippine coast. The preexisting paradigm for such system depicts that the subthermocline flows are a mirror image of the wind-driven thermocline circulation with a North Equatorial Undercurrent (NEUC) directing eastward beneath the NEC, a poleward-moving Mindanao Undercurrent (MUC) underlying the Mindanao Current, and an equatorward Luzon Undercurrent (LUC) flowing below the Kuroshio.

In contrast to this mirror image pattern, our analyses revealed that the subthermocline western boundary circulation off the Philippine coast comprises two components that have different meridional scales and generation mechanisms. The first component has a meridional scale shorter than $400 \mathrm{~km}$ and is characterized by convergent meridional flows near $7^{\circ}, 10^{\circ}, 13^{\circ}$, and $18^{\circ} \mathrm{N}$ along the western boundary (see the schematic in Fig. 14a). Away from the western boundary, these convergent meridional flows are drawn by the eastwardflowing zonal jets that extend across the entire North Pacific basin. Dynamically, these interior zonal jets are formed by eddy-eddy interactions in the eastern North Pacific basin where wind-forced annual baroclinic Rossby waves break down due to the nonlinear triad instability. The $O(400) \mathrm{km}$ separation scale between the eastward zonal jets is set by the most unstable secondary waves involved in the triad stability (Qiu et al. 2013a). 
(a) Mean PV Adv: 26.8-27.5 $\sigma_{\theta}$

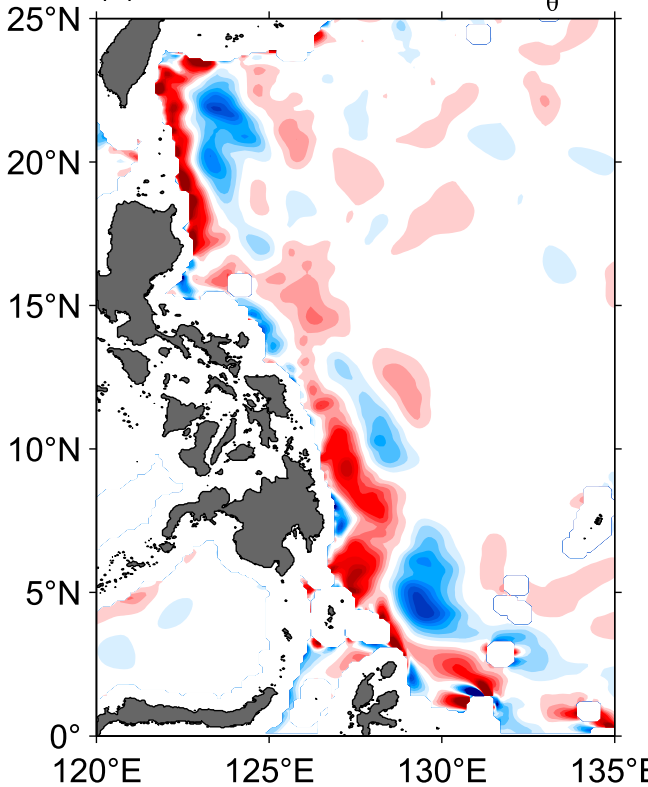

(b) Eddy PV Flux Divergence

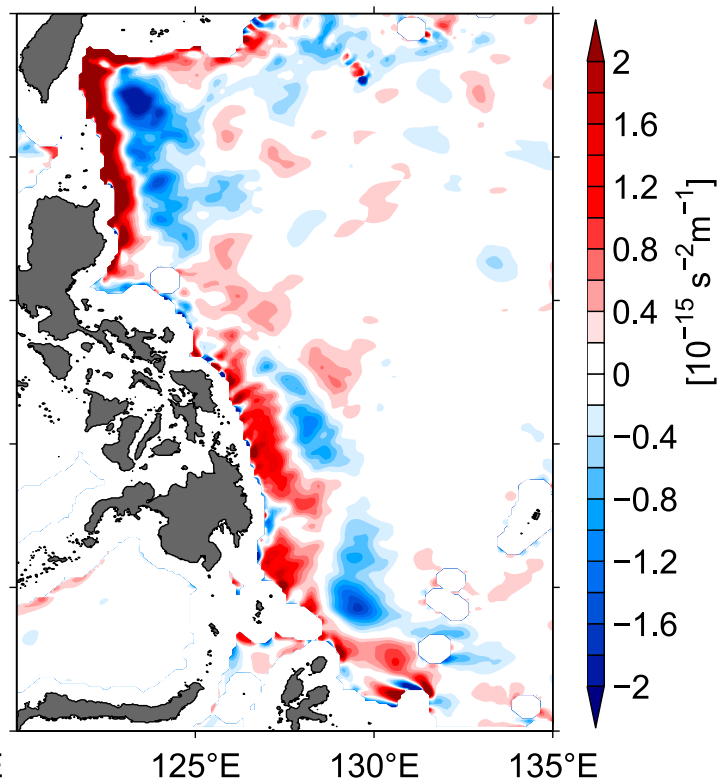

(d) OFES mean $\mathrm{V}$

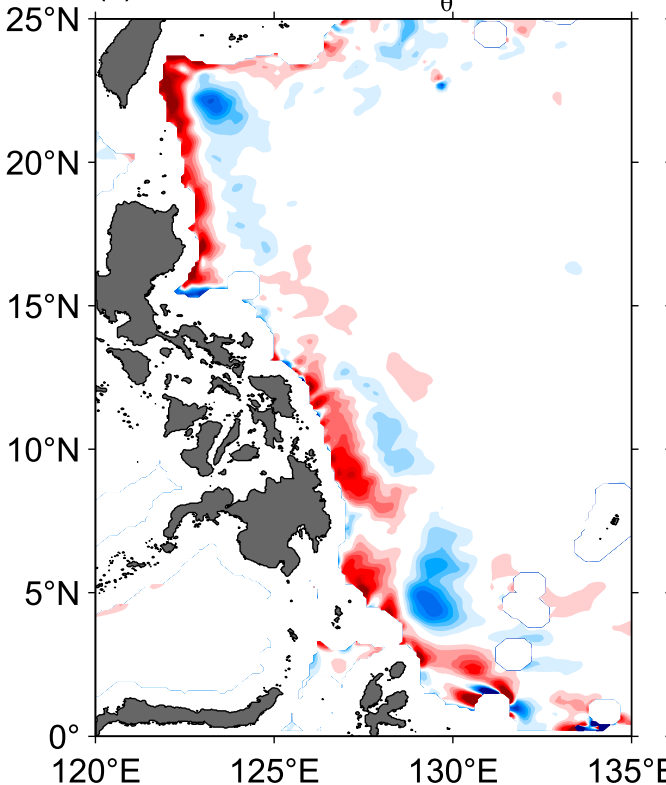

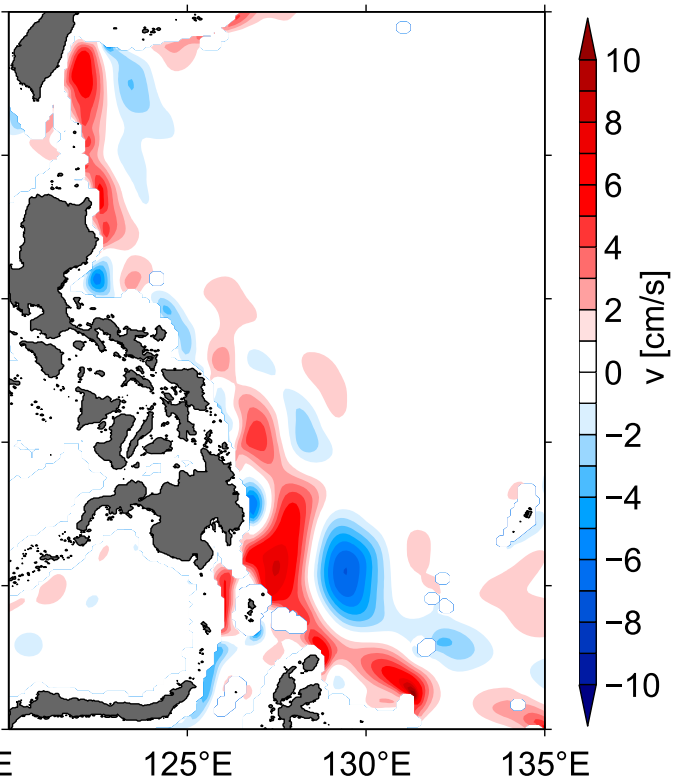

FIG. 12. Distributions of (a) $\overline{\mathbf{u}} \cdot \nabla \bar{Q}$ and (b) $-\nabla \cdot\left(\overline{\mathbf{u}^{\prime} Q^{\prime}}\right)$ evaluated in the 26.8-27.5 $\sigma_{\theta}$ layer from the OFES simulation. (c) Distribution of $\bar{v}$ calculated from the approximate turbulent Sverdrup balance $-\nabla \cdot\left(\overline{\mathbf{u}^{\prime} Q^{\prime}}\right) /(\partial \bar{Q} / \partial y)$. (d) Distribution of $\bar{v}$ in the 26.8-27.5 $\sigma_{\theta}$ layer from the OFES simulation.

Through mass conservation, the convergent meridional flows along the Philippine coast are the western boundary expression of these interior ocean instabilitydriven zonal jets.

The second component of the subthermocline western boundary circulation has a broader meridional scale and consists of coherent northward flows along the boundary segments of $6^{\circ}-13^{\circ} \mathrm{N}$ and $16^{\circ}-24^{\circ} \mathrm{N}$ (see Fig. $14 \mathrm{~b}$ for a schematic). In terms of nomenclature, the northward flow along the $6^{\circ}-13^{\circ} \mathrm{N}$ segment corresponds to the MUC described by many previous investigators. Unlike the short-scale meridional flows forced remotely from the interior North Pacific Ocean, these broad-scale northward boundary flows are generated locally by the 
(a) BC Rate: Surface-26.8 $\sigma_{\theta}$

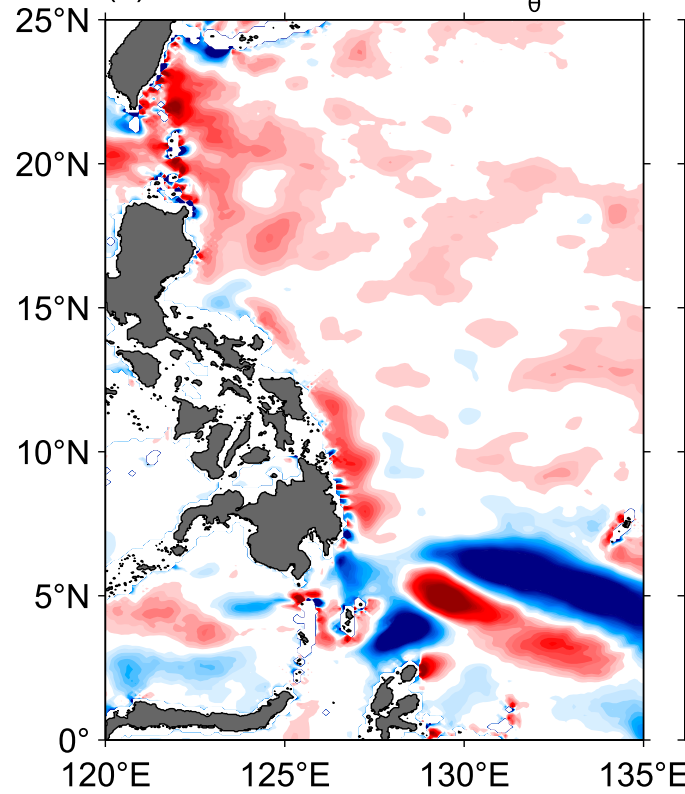

(c) BC Rate: $26.8-27.5 \sigma_{\theta}$

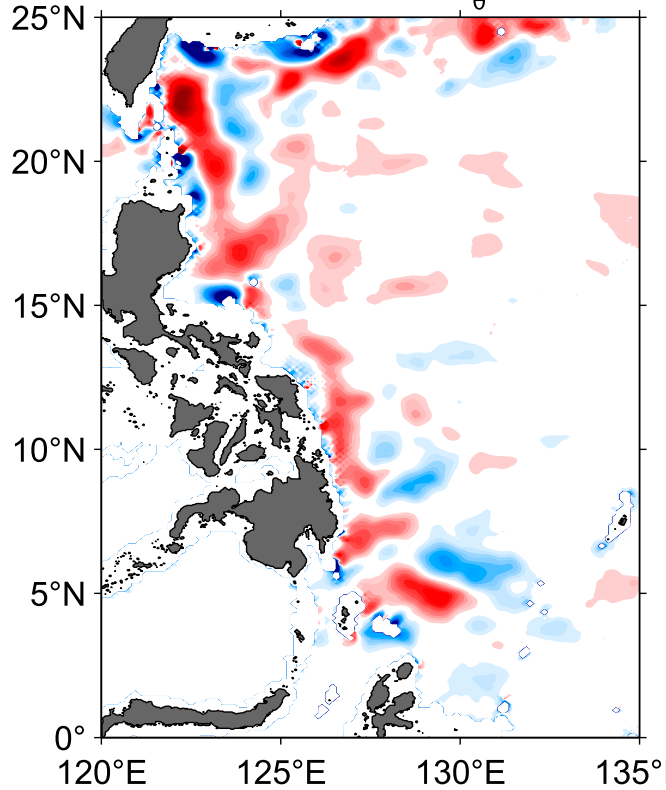

(b) BT Rate: Surface $-26.8 \sigma_{\theta}$

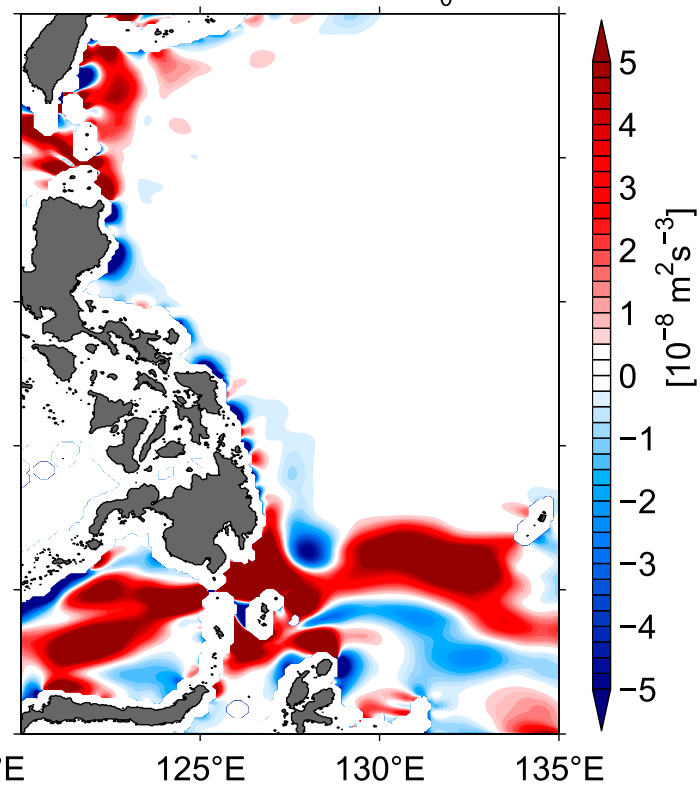

(d) BT Rate: $26.8-27.5 \sigma_{\theta}$

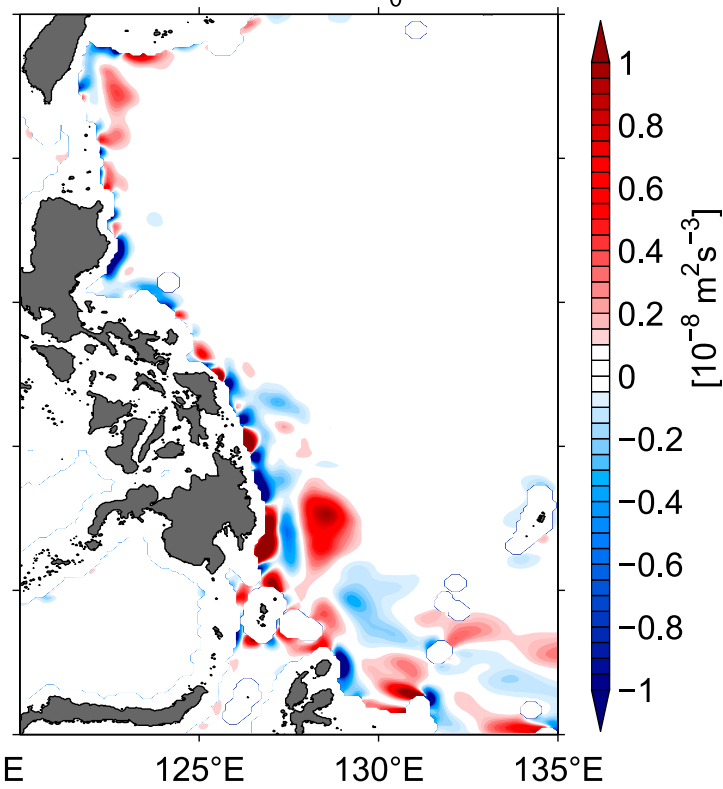

FIG. 13. Distributions of (a) baroclinic conversion rate and (b) barotropic conversion rate in the thermocline layer of surface to $26.8 \sigma_{\theta}$. (c),(d) As in (a) and (b), but for the subthermocline layer of 26.8-27.5 $\sigma_{\theta}$.

eddy PV flux convergence along the western boundary. By analyzing the output from the eddy-resolving OFES simulation, we found that these regional eddy fluxes were generated by baroclinic instability that derives its energy from the mean thermocline tilt of the wind-driven Mindanao Current and Kuroshio. Notice that the eddy $\mathrm{PV}$ convergence, hence the eddy-driven subthermocline boundary current, is weak in the $13^{\circ}-16^{\circ} \mathrm{N}$ segment because this is where the vertically averaged NEC bifurcates and where the thermocline tilts associated with the Mindanao Current and Kuroshio are weak.

It is worth stressing that while differing in their energy source, both components of the subthermocline boundary flows are in essence eddy driven. Given this, any short-term observations of these boundary flows in the region are likely to be aliased by transient eddy 
(a) Length Scale $\leq \mathrm{O}(400 \mathrm{~km})$

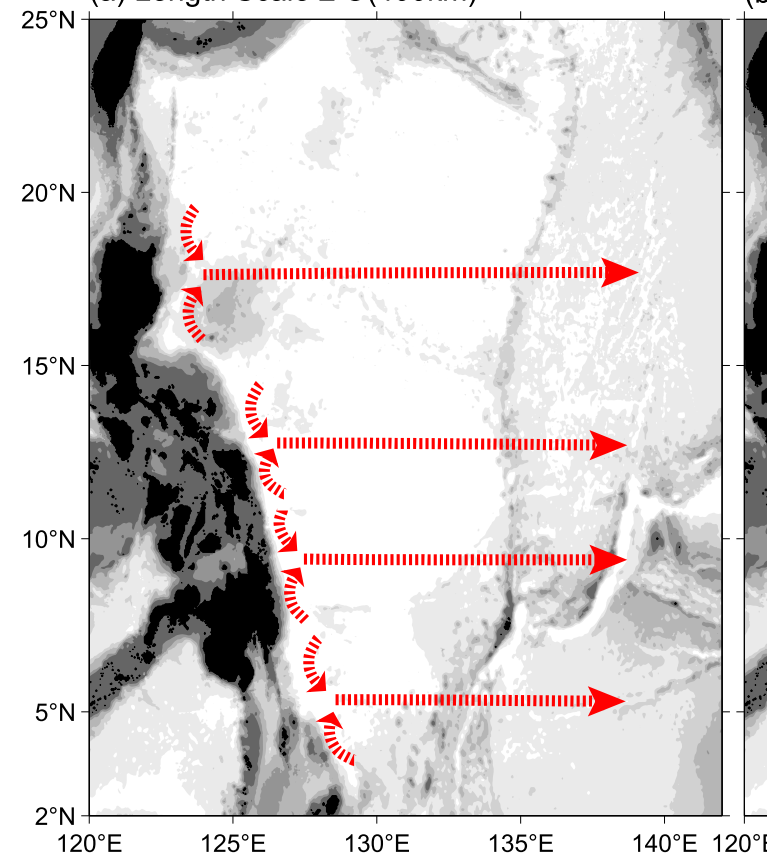

(b) Length Scale $>\mathrm{O}(400 \mathrm{~km})$

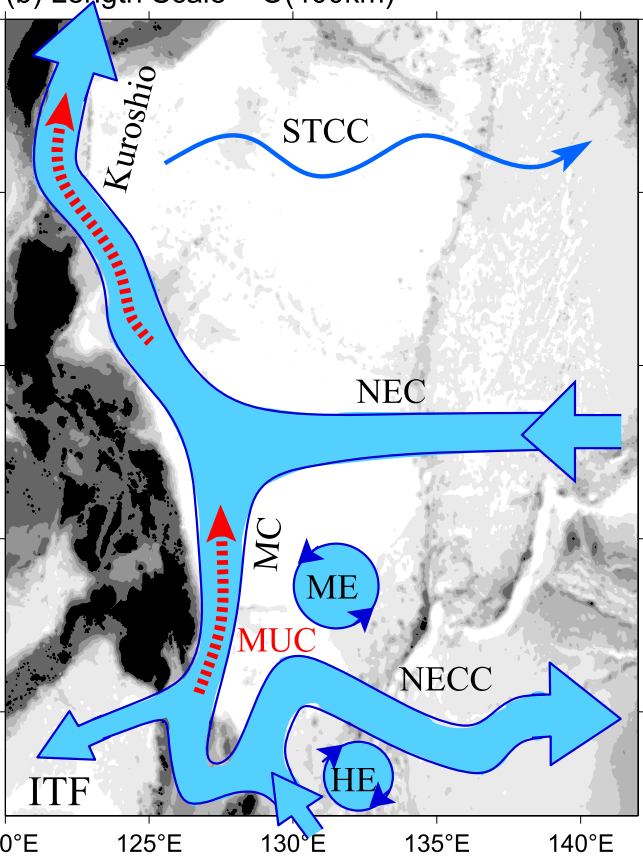

FIG. 14. Newly observed circulation features in the subthermocline layer of 26.8-27.5 $\sigma_{\theta}$ (red arrows) in the western North Pacific Ocean. Flows with meridional scales shorter and longer than $400 \mathrm{~km}$ are sketched in (a) and (b), respectively. Blue arrows in (b) represent the circulation features in the ventilated thermocline (depth $<400 \mathrm{~m}$; see Fig. 1 for acronyms).

signals. To verify the new subthermocline circulation paradigm proposed in this study and to further our understanding of the subthermocline regional circulation variability, long-term and spatially coordinated future observations are called for.

Acknowledgments. This study benefitted from discussions with Mike Spall and Seth Travis. We thank the anonymous reviewers whose detailed comments helped improve an early version of the manuscript. The Argo profiling float data used in this study were provided by the U.S. GODAE Argo Global Data Assembly Center and the historical $T-S$ data by U.S. National Oceanographic Data Center (NODC) and Japan Oceanographic Data Center (JODC). This study was supported by the ONR project Origins of the Kuroshio and Mindanao Current (OKMC): N00014-10-1-0267 (BQ and SC) and N00014-10-1-0273 (DLR). Arnold Gordon generously supplied additional in situ $T-S$ data from the recent OKMC cruises.

\section{REFERENCES}

Andres, M., J.-H. Park, M. Wimbush, X.-H. Zhu, K.-I. Chang, and H. Ichikawa, 2008: Study of the Kuroshio/Ryukyu Current system based on satellite-altimeter and in situ measurements. J. Oceanogr., 64, 937-950, doi:10.1007/s10872-008-0077-2.
Centurioni, L. R., P. P. Niiler, and D.-K. Lee, 2004: Observations of inflow of Philippine Sea surface water into the South China Sea through the Luzon Strait. J. Phys. Oceanogr., 34, 113-121, doi:10.1175/1520-0485(2004)034<0113:OOIOPS >2.0.CO;2.

Chen, S., B. Qiu, and P. Hacker, 2007: Profiling float measurements of the recirculation gyre south of the Kuroshio Extension in May to November 2004. J. Geophys. Res., 112, C05023, doi:10.1029/2006JC004005.

Cravatte, S., W. S. Kessler, and F. Marin, 2012: Intermediate zonal jets in the tropical Pacific Ocean observed by Argo floats. J. Phys. Oceanogr., 42, 1475-1485, doi:10.1175/ JPO-D-11-0206.1.

Firing, E., Y. Kashino, and P. Hacker, 2005: Energetic subthermocline currents observed east of Mindanao. Deep-Sea Res., 52, 605-613, doi:10.1016/j.dsr2.2004.12.007.

Gilson, J., and D. Roemmich, 2002: Mean and temporal variability in the Kuroshio geostrophic transport south of Taiwan (1993-2001). J. Oceanogr., 58, 183-195, doi:10.1023/ A:1015841120927.

Gordon, A. L., and R. A. Fine, 1996: Pathways of the water between the Pacific and Indian Oceans in the Indonesian seas. Nature, 379, 146-149, doi:10.1038/379146a0.

—, P. Flament, C. Villanoy, and L. Centurioni, 2014: The nascent Kuroshio of Lamon Bay. J. Geophys. Res. Oceans, 119, 42514263, doi:10.1002/2014JC009882.

Hu, D., and M. Cui, 1991: The western boundary current of the Pacific and its role in the climate. Chin. J. Oceanol. Limnol., 9, 1-14, doi:10.1007/BF02849784.

, and Coauthors, 2013: Direct measurements of the Luzon Undercurrent. J. Phys. Oceanogr., 43, 1417-1425, doi:10.1175/ JPO-D-12-0165.1. 
Huang, R. X., and B. Qiu, 1994: Three-dimensional structure of the wind-driven circulation in the subtropical North Pacific. J. Phys. Oceanogr., 24, 1608-1622, doi:10.1175/1520-0485(1994)024<1608: TDSOTW $>2.0 . \mathrm{CO} ; 2$.

Ichikawa, H., H. Nakamura, A. Nishina, and M. Higashi, 2004: Variability of north-eastward current southeast of northern Ryukyu Islands. J. Oceanogr., 60, 351-363, doi:10.1023/ B:JOCE.0000038341.27622.73.

Imawaki, S., A. S. Bower, L. Beal, and B. Qiu, 2013: Western boundary currents. Ocean Circulation and Climate: A 21st Century Perspective, 2nd ed., G. Siedler et al., Eds., Academic Press, 305-338.

Johns, W. E., T. N. Lee, D. X. Zhang, R. Zantopp, C. T. Liu, and Y. Yang, 2001: The Kuroshio east of Taiwan: Moored transport observations from the WOCE PCM-1 array. J. Phys. Oceanogr., 31, 1031-1053, doi:10.1175/1520-0485(2001)031<1031: TKEOTM $>2.0 . \mathrm{CO} ; 2$.

Kashino, Y., E. Firing, P. Hacker, A. Sulaiman, and Lukiyanto, 2001: Currents in the Celebes and Maluku Seas, February 1999. Geophys. Res. Lett., 28, 1263-1266, doi:10.1029/ 2000GL011630.

_ - A. Ishida, and Y. Kuroda, 2005: Variability of the Mindanao Current: Mooring observation results. Geophys. Res. Lett., 32, L18611, doi:10.1029/2005GL023880.

_- A. Atmadipoera, Y. Kuroda, and Lukijanto, 2013: Observed features of the Halmahera and Mindanao eddies. J. Geophys. Res. Oceans, 118, 6543-6560, doi:10.1002/2013JC009207.

Kim, Y., T. Qu, T. Jensen, T. Miyama, H. Mitsudera, H. Kang, and A. Ishida, 2004: Seasonal and interannual variations of the North Equatorial Current bifurcation in a high-resolution OGCM. J. Geophys. Res., 109, C03040, doi:10.1029/2003JC002013.

Kistler, R., and Coauthors, 2001: The NCEP-NCAR 50-Year Reanalysis: Monthly means CD-ROM and documentation. Bull. Amer. Meteor. Soc., 82, 247-267, doi:10.1175/ 1520-0477(2001)082<0247:TNNYRM > 2.3.CO;2.

Kobashi, F., and H. Kawamura, 2002: Seasonal variation and instability nature of the North Pacific Subtropical Countercurrent and the Hawaiian Lee Countercurrent. J. Geophys. Res., 107, 3185, doi:10.1029/2001JC001225.

, and A. Kubokawa, 2012: Review on North Pacific Subtropical Countercurrents and Subtropical Fronts: Role of mode waters in ocean circulation and climate. J. Oceanogr., 68, 21-43, doi:10.1007/s10872-011-0083-7.

Lebedev, K. V., H. Yoshinari, N. A. Maximenko, and P. W. Hacker, 2007: YoMaHa'07: Velocity data assessed from trajectories of Argo floats at parking level and at the sea surface. IPRC Tech. Note 4, 16 pp.

Lee, T. N., W. E. Johns, C.-T. Liu, D. Zhang, R. Zantopp, and Y. Yang, 2001: Mean transport and seasonal cycle of the Kuroshio east of Taiwan with comparison to the Florida Current. J. Geophys. Res., 106, 22 143-22 158, doi:10.1029/ 2000JC000535.

Lien, R.-C., B. Ma, Y.-H. Cheng, C.-R. Ho, B. Qiu, C. M. Lee, and M.-H. Chang, 2014: Modulation of Kuroshio transport by mesoscale eddies at the Luzon Strait entrance. J. Geophys. Res. Oceans, 119, 2129-2142, doi:10.1002/2013JC009548.

Locarnini, R. A., and Coauthors, 2013: Temperature. Vol. 1, World Ocean Atlas 2013, NOAA Atlas NESDIS 73, 40 pp.

Lukas, R., E. Firing, P. Hacker, P. L. Richardson, C. A. Collins, R. A. Fine, and R. Gammon, 1991: Observations of the Mindanao Current during the western equatorial Pacific Ocean circulation study. J. Geophys. Res., 96, 7089-7104, doi:10.1029/91JC00062.
Nakamura, H., H. Ichikawa, and A. Nishina, 2007: Numerical study of the dynamics of the Ryukyu Current system. J. Geophys. Res., 112, C04016, doi:10.1029/2006JC003595.

Park, J. J., K. Kim, B. A. King, and S. C. Riser, 2005: An advanced method to estimate deep currents from profiling floats. J. Atmos. Oceanic Technol., 22, 1294-1304, doi:10.1175/ JTECH1748.1.

Pedlosky, J., 1987: Geophysical Fluid Dynamics. 2nd ed. SpringerVerlag, 710 pp.

Qiu, B., 1999: Seasonal eddy field modulation of the North Pacific Subtropical Countercurrent: TOPEX/POSEIDON observations and theory. J. Phys. Oceanogr., 29, 2471-2486, doi:10.1175/1520-0485(1999)029<2471:SEFMOT>2.0.CO;2.

— 2001: Kuroshio and Oyashio Currents. Encyclopedia of Ocean Sciences, Academic Press, 1413-1425.

_ the North Equatorial Current, the Mindanao Current and the Kuroshio along the Pacific western boundary. J. Geophys. Res., 101, 12315-12 330, doi:10.1029/95JC03204.

_ S. Chen, and H. Sasaki, 2013a: Generation of the North Equatorial Undercurrent jets by triad baroclinic Rossby wave interactions. J. Phys. Oceanogr., 43, 2682-2698, doi:10.1175/ JPO-D-13-099.1.

— D. L. Rudnick, S. Chen, and Y. Kashino, 2013b: Quasistationary North Equatorial Undercurrent jets across the tropical North Pacific Ocean. Geophys. Res. Lett., 40, 2183-2187, doi:10.1002/grl.50394.

Qu, T., and R. Lukas, 2003: The bifurcation of the North Equatorial Current in the Pacific. J. Phys. Oceanogr., 33, 5-18, doi:10.1175/1520-0485(2003)033<0005:TBOTNE >2.0.CO;2.

_, T. Kagimoto, and T. Yamagata, 1997: A subsurface countercurrent along the east coast of Luzon. Deep-Sea Res., 44, 413-423, doi:10.1016/S0967-0637(96)00121-5.

— H. Mitsudera, and T. Yamagata, 1998: On the western boundary currents in the Philippine Sea.J. Geophys. Res., 103, 7537-7548, doi:10.1029/98JC00263.

Rhines, P. B., and W. R. Holland, 1979: A theoretical discussion of eddy-driven mean flows. Dyn. Atmos. Oceans, 3, 289-325, doi:10.1016/0377-0265(79)90015-0.

Roemmich, D., and Coauthors, 2009: The Argo program: Observing the global ocean with profiling floats. Oceanography, 22, 34-43, doi:10.5670/oceanog.2009.36.

Sasaki, H., M. Nonaka, Y. Masumoto, Y. Sasai, H. Uehara, and H. Sakuma, 2008: An eddy-resolving hindcast simulation of the quasi-global ocean from 1950 to 2003 on the Earth Simulator. High Resolution Numerical Modelling of the Atmosphere and Ocean, W. Ohfuchi and K. Hamilton, Eds., Springer, 157-185.

Schönau, M. C., and D. L. Rudnick, 2015: Glider observations of the North Equatorial Current in the western tropical Pacific. J. Geophys. Res. Oceans, 120, 3586-3605, doi:10.1002/ 2014JC010595.

Talley, L. D., 1985: Ventilation of the subtropical North Pacific: The shallow salinity minimum. J. Phys. Oceanogr., 15, 633-649, doi:10.1175/1520-0485(1985)015<0633:VOTSNP>2.0.CO;2.

Toole, J. M., E. Zou, and R. C. Millard, 1988: On the circulation of the upper waters in the western equatorial $\mathrm{Pa}$ cific Ocean. Deep-Sea Res., 35, 1451-1482, doi:10.1016/ 0198-0149(88)90097-0.

Vianna, M. L., and V. V. Menezes, 2010: Mean mesoscale global ocean currents from geodetic pre-GOCE MDTs with a synthesis of the North Pacific circulation. J. Geophys. Res., 115, C02016, doi:10.1029/2009JC005494. 
Wang, F., D. Hu, and H. Bai, 1998: Western boundary undercurrents east of the Philippines. Proc. Fourth Pacific Ocean Remote Sensing Conf., Qingdao, China, PORSEC, 551-556.

-, N. Zang, Y. Li, and D. Hu, 2015: On the subsurface countercurrents in the Philippine Sea. J. Geophys. Res. Oceans, 120, 131-144, doi:10.1002/2013JC009690.

Wang, Q., F. Zhai, and D. Hu, 2014: Variations of Luzon Undercurrent from observations and numerical model simulations. J. Geophys. Res. Oceans, 119, 3792-3805, doi:10.1002/2013JC009694.

Wijffels, S., E. Firing, and J. Toole, 1995: The mean structure and variability of the Mindanao Current at $8^{\circ}$ N. J. Geophys. Res. 100, 18 421-18 435, doi:10.1029/95JC01347.

Zhang, D., T. N. Lee, W. E. Johns, C.-T. Liu, and R. Zantopp, 2001: The Kuroshio east of Taiwan: Modes of variability and relationship to interior ocean mesoscale eddies. J. Phys. Oceanogr., 31, 1054-1074, doi:10.1175/1520-0485(2001)031<1054: TKEOTM $>2.0 . \mathrm{CO} ; 2$.

Zhang, L., D. Hu, S. Hu, F. Wang, F. Wang, and D. Yuan, 2014: Mindanao Current/Undercurrent measured by a subsurface mooring. J. Geophys. Res. Oceans, 119, 3617-3628, doi:10.1002/ 2013JC009693.

Zhu, X.-H., I.-S. Han, J.-H. Park, H. Ichikawa, K. Murakami, A. Kaneko, and A. Ostrovskii, 2003: The northeastward current southeast of Okinawa Island observed during November 2000 to August 2001. Geophys. Res. Lett., 30, 1071, doi:10.1029/ 2002 GL015867.

Zweng, M. M., and Coauthors, 2013: Salinity. Vol. 2, World Ocean Atlas 2013, NOAA Atlas NESDIS 74, 39 pp. 